CUADERNOS DE ESTUDIOS GALLEGOS, LVIII N. ${ }^{\circ} 124$, enero-diciembre (2011), pp. 29-78

ISSN 0210-847 X

\title{
AS PARROQUIAS DO PORRIÑO, CANS E ATIOS NA DOCUMENTACIÓN DO MOSTEIRO CISTERCIENSE DE SANTA MARÍA DE MELÓN. SÉCULOS XII E XIII
}

ISIS GRADÍN FERNÁNDEZ

Miguel ROMANí MARTÍNEZ

Universidade de Santiago de Compostela 


\title{
AS PARROQUIAS DO PORRIÑO, CANS E ATIOS NA DOCUMENTACIÓN DO MOSTEIRO CISTERCIENSE DE SANTA MARÍA DE MELÓN. SÉCULOS XII E XIII*
}

\begin{abstract}
RESUMEN
Trala introducción e criterios de transcripción, edítanse 31 documentos dos séculos XII e XIII pertencentes ó mosteiro cisterciense de Santa María de Melón, concretamente aqueles que permiten reconstruír as antigas posesións -centradas sobre o actual concello de O Porriño- do que foi o mosteiro de San Miguel de Cans, absorvido polos monxes cistercienses de Melón. Faise unha aproximación paleográfica e histórica da documentación, que se complementa cos correspondentes índices onomásticos e toponímicos.
\end{abstract}

PAlabRas ClaVe: Paleografía, Mosteiro, Císter.

\section{THE PARISHES OF PORRIÑO, CANS AND ATIO IN THE DOCUMENTATION OF THE CISTERCIAN MONASTERY OF SANTA MARIA DE MELON. $12^{\text {th }}$ AND $13^{\text {th }}$ CENTURIES}

\begin{abstract}
After the introduction and criteria of transcription, 31 papers are published from the twelfth and thirteenth centuries belonging to the Cistercian monastery of Santa Maria de Melon, specifically those that permit the reconstruction of old possessions, focusing on the current council of O Porriño -which was the monastery of San Miguel de Cans, absorbed by the cistercian monks of Melon. A paleographic and historical approximation of this documentation is done, which is complemented with the corresponding index of names and place names.
\end{abstract}

KEY WORDS: Paleography, Monastery, Cister.

\footnotetext{
* El presente estudio se enmarca dentro del proyecto Linaje, parentela y poder: la pirámide nobiliaria gallega (siglos XIII al XV) I (MICIIN, Plan Nacional de I+D+I. Ref. HAR2010-18378), del que es investigador principal Eduardo Pardo Guevara y Valdés.
} 
Recibido/Received: 08/07/2011

Aceptado/Accepted: 27/07/2011

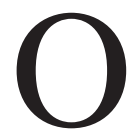

antigo mosteiro cisterciense de Santa María de Melón atópase no límite occidental da actual provincia de Ourense, moi próximo á actual provincia de Pontevedra. Tradicionalmente asúmese que foi unha fundación feita por monxes chegados de Claraval, o que parece confirmar o nome claramente extrapeninsular do seu primeiro abade, Giraldus. Os monxes cistercienses chegarían por primeira vez a Galicia en 1142, e algún tempo despois enviaríase unha segunda remesa dende Borgoña. O mosteiro de Melón non partiría de ningún cenobio anterior, ou -no caso de que así fora-os recén chegados decidiron edifica-lo seu noutro lugar. A este respeto, plantéxase a posibilidade de que inicialmente os cistercienses ocuparan o cenobio de Barcia ata a construcción dun novo mosteiro, que sería o de Melón. En 1154 a comunidade xa estaba constituída, e rapidamente iniciará unha expansión que a levará a ter propiedades por toda a Galicia meridional, dende o val do Támega ata a ría de Vigo, entre as que se atopan os mosteiros anexados de Santa María de Barcia e San Miguel de Cans. A zona escollida para este traballo representa as antigas posesións deste último mosteiro, doado polo seu abade Pedro Cortina á súa morte ó abade Xiraldo de Melón, chegándose a un novo acordo en 1165 polo que se convertía nunha granxa melonense ${ }^{1}$. Os documentos relativos ós inicios do mosteiro de Melón foron recompilados no seu momento polo profesor Miguel Romaní2.

O municipio de O Porriño ubícase ao Sur da provincia de Pontevedra, limitando ó Norte co municipio de Mos, ó Noroeste co de Vigo, ó Oeste co de Gondomar, ó Sur coa cidade de Tui, ó Sueste co municipio de Salceda de Caselas, e ó Leste co

\footnotetext{
1 Véxase PÉREZ RODRÍGUEZ, F. J., Mosteiros de Galicia na Idade Media, 2008, pp. 192-195.

2 Véxase ROMANÍ MARTÍNEZ, M. e OTERO PIÑEYRO MASEDA, P. S., "Sobre los inicios del monasterio de Melón y sus relaciones con los monasterios de Bárcena y Canales: corpus documental", Galicia monástica. Homenaxe a María José Portela Silva, Universidade de Santiago de Compostela, 2009, pp. 23-37.
} 
de Ponteareas. O presente estudo inclue os documentos dos séculos XII e XIII relativos ó concello de O Porriño, e máis concretamente os que se relacionan coas actuais parroquias de Santa María de O Porriño, Santo Estevo de Cans e Santa Eulalia de Atios, xunto a outras parroquias do lindante concello de Mos.

\section{ASPECTOS DOCUMENTAIS E DIPLOMÁTICOS}

Nos documentos estudados destacan polo seu volume as compravendas, sendo un total de trece, as cales se corresponden ós documentos n. ${ }^{\text {os }} 3,6,7,9,14,18$, $19,20,21,22,23,24$ e 26, seguidas das cartas de foro, cuxo número ascende a nove, correspondéndose cos documentos n. ${ }^{\text {os }} 10,11,13,15,16,17,27,30$ e 31. As doazóns son un total de catro, correspondéndose ós n. ${ }^{\text {os }} 1,2,12$ e 25 . Tres son as contendas, que se corresponden ós n. ${ }^{\text {os }} 8$ (dissensio), 28 (convenirunt in iudicium) e 29 (preito). Por último atopamos unha carta de poder no documento n. ${ }^{\circ} 4$ e un acordo (pactum et placitum) no n. ${ }^{\circ} 5$.

A formulación diplomática dos documentos estudados é xa a característica de finais do século XII, na que apenas quedan recordos da formulación visigótica. En xeral presentan as partes características, é dicir, protocolo, con invocacións, intitulacións e direccións moi sinxelas, pasando rapidamente ó dispositivo verbal, onde expresan o tipo de acto xurídico que se vai realizar, seguindo a continuación o dispositivo documental no que se explican os aspectos concretos e as circunstancias características ou propias de cada documento en si. Seguen a continuación as corroboracións, pasando á última parte do documento, o escatocolo, mediante as fórmulas da data, expresada mediante a era hispánica en números romanos, á que segue a data histórica que comprende polo xeral o regnante, o bispo e segundo os casos algún tenente terrae. Seguen as sancións, encabezadas por si quis, coas que se trata de que ninguén infrinxa o establecido no documento, aludindo ás penas morais e económicas en que poderá incorrer o infractor. Seguidamente vén a relación de testemuñas e confirmantes, neste último caso nos documentos máis antigos. O documento féchase coa subscripción do amanuense.

\section{APROXIMACIÓN PALEOGRÁFICA}

A colección diplomática está composta por trinta e un documentos, deles dezanove son orixinais e doce copias simples procedentes do tumbo n. ${ }^{\circ}$ 325-B do AHN, dos cales non puidemos achar o seu correspondente orixinal. As características paleográficas, polo tanto só poderán facerse sobre os pergameos orixinais conservados. Os documentos están na súa maioría escritos en latín, agás os n. ${ }^{\text {os }} 24,25,26,27,29,30$ e 31, que están en galego, destacando este último pola súa rusticidade e por estar escrito nun galego moi interesante a efectos filolóxicos. 
Evidentemente pola cantidade de documentos que temos non podemos sacar grandes conclusións, non obstante de entrada si que pode dicirse que tódolos documentos pertencen ó ciclo da escritura gótica. Os seis primeiros documentos orixinais, comprendidos entre 1181 e 1243 , acusan certo arcaísmo no seu trazado fronte ós demais, e entre eles pódense destacar o n. 9 e o n. ${ }^{\circ} 10$, cuxo estilo é máis librario ca documental. Dito isto, pódese falar de que estamos ante o que poderiamos conceptuar de forma xeral como unha gótica documental que implica maior ou menor cursividade, sen excluír que o trazado dalgúns documentos poida resultar caligrafiado, e xunto a estes tipos pódense atopar, como xa dixemos, algúns documentos que mostran escrituras certamente máis librarias ca documentais.

Ademais, como xa citara Manuel Lucas Álvarez ${ }^{3}$, é posible observar na escritura deste período escrituras máis angulosas e escrituras máis redondeadas, ou ben outras máis alargadas xunto a escrituras máis baixas, ou escrituras con marcados contrates e outras cun trazado máis uniforme; o mesmo pode dicirse respecto a escrituras máis sinxelas que conviven xunto a outras que tenden a curva-los seus alzados e caídos, e tamén podería dicirse da existencia de escrituras máis cursivas e outras máis sentadas. En resumo, esta variedade é a que se observa nos pergameos que forman parte desta pequena colección diplomática.

\section{ASPECTOS HISTÓRICOS E SOCIAIS}

O actual concello de O Porriño está integrado por oito parroquias, das cales neste traballo interésannos tan só tres, que son aquelas que aparecen mencionadas nos documentos consultados do mosteiro de Melón: Santa María de O Porriño, Santa Eulalia de Atios e Santo Estevo de Cans. Aínda que a primeira non a atopamos mencionada explicitamente como parroquia, aparece o topónimo O Porriño nos docs. n. ${ }^{\text {os }}$ 19, 20, 22, 23, 26, 29 e 31. A de Santa Eulalia de Atios atopámola nos docs. n. ${ }^{\text {os }} 2,4,5,26$ e 28, e xunto a ela os actuais lugares de O Castro no doc. $\mathrm{n}^{\mathrm{o}} 19$ e do Rial nos docs. n. $^{\text {os }} 24,25$ e 30 . Á actual parroquia de Santo Estevo de Cans faise referencia nun elevado n. ${ }^{\circ}$ de docs.: 3, 4, 5, 7, 11, 12 , $13,15,16,17,18,20,22,23,24,25,27,28,29,30$ e 31, e ó lugar da Graña desa mesma parroquia no doc. n. $^{\circ} 30$.

Fóra do actual concello de O Porriño, méntanse ademais algunhas parroquias do concello de Mos que lindan co de O Porriño, como a de Santa María de Sanguiñeda, que a atopamos nos docs. n. ${ }^{\text {os }} 4,14$ e 29, aparecendo tamén neste

\footnotetext{
${ }^{3}$ LUCAS ÁLVAREZ, Manuel, "Paleografía gallega. Estado de la cuestión", Anuario de Estudios Medievales, $\mathrm{n}^{\circ}$ 21, 1991, pp. 527-536, especialmente o apartado adicado á producción documental (pp. 450-451).
} 
último doc. o lugar de Ameiro Longo, pertencente a esta mesma parroquia; a parroquia de San Miguel de Pereiras méntase nos docs. n. ${ }^{\text {os }}$ 1, 8, 9, 10, 11, 12 e 29; por último, e un pouco máis lonxe, atopamos o actual lugar de Santa Marta, pertencente á parroquia de Santa Eulalia de Mos, nos docs. n. ${ }^{\text {os }}$ 4, 5,7 e 28.

En canto ás xurisdiccións reais e ós territorios onde está representado o rei destacan as terras á fronte das cales está un tenente, como é a da Limia, no sector suroccidental da provincia de Ourense que viría a coincidir en xeral coa actual comarca da Limia e que atopamos nos docs. n. ${ }^{\text {os }} 1,9,10$ e 28 ; e especialmente a terra de Toroño, que a grandes riscos abarcaría o territorio da diocese de Tui e que aparece nos docs. n. ${ }^{\text {os }} 4,15,16,17,18,29$ e 31 . Outra terra á fronte da cal hai un tenente, pero que non puidemos localizar, é Turia, que se menciona no doc. n. ${ }^{\circ} 6$.

Como terras menores dentro da de Toroño atopamos a terra de Entenza, comarca histórica do sur da provincia de Pontevedra con cabeceira en Salceda de Caselas e que contaba cun castelo aparece nos docs. n. ${ }^{\text {os }} 7$ e 24 ; a terra da Louriña, que abarcaría o que hoxe é o Val da Louriña atopámola nos docs. n. ${ }^{\text {os }}$ $15,19,20,21,22,23,24,25,26,29,30$ e 31.

Analizaremos agora as figuras máis relevantes atopadas na documentación, que estructuraremos en torno a catro apartados: clero regular, clero secular, cargos cívico-militares e escribáns e notarios. Cabe destacar que os tres primeiros grupos atopámolos principalmente na data histórica.

\section{Clero regular}

En canto ó clero regular centrarémonos principalmente nos oficios monásticos de Melón, ou naqueles que dun xeito ou outro están vencellados a este mosteiro. Os abades atopados suman once, que a continuación presentamos xunto ós seus subordinados.

O primeiro abade de Melón que atopamos na documentación é don Martín, entre o 25 de xuño de 1174 e 1185, docs. 1 e 3, aparecendo tamén como escribán nos dous primeiros documentos da colección. Durante o período do seu mandato atopamos dúas cartas de doazón nos docs. 1 e 2 e unha compravenda no doc. 3. Xunto a el unicamente aparece en 1185 un frade, Afonso Petriz de Molin, no doc. 3.

O seguinte abade, don Pedro aparece o 4 de febreiro 1189, ano no que se realiza unha carta de poder, doc. 4, aparecendo xunto a el Laurentius Martini e Petrus Ioannis coma monxes do seu mosteiro, e Ioannes coma monxe de Santa Marta.

Outro Pedro aparece coma abade de Melón en agosto de 1219, ano no que se realiza un acordo, doc. 5. Atopamos xunto a el Petrus como prior, Petrus como 
sancristán, Fernandus Arie como boticario, Ioannes como enfermeiro, Fernandus como celareiro, Rodericus como vestiario e Rodericus Martini como contralorum (termo do que descoñecemo-lo seu significado).

Don Vermudo está exercendo como abade de Melón o 29 de marzo de 1223, realizándose durante o seu mandato unha compravenda, doc. 6. Xunto a el están ese mesmo ano Gomecius como prior, Fernandus como subprior, Michael como boticario, Petrus como subenfermeiro, Petrus Ramirit como porteiro, Fernandus Munionis e Arias Garcie como conversos e por último Menendus Arie como monxe.

O seguinte abade do que temos noticia é Gómez, entre o 19 de maio de 1231 e o 9 de xaneiro 1233, período no cal atopamos unha compravenda e unha carta de foro nos docs. 9 e 10. Xunto a el aparecen Fernandus Calvus como prior en 1231 e 1233, Petrus Nunioni como subprior en 1233, Iohannes Iohannis como celareiro en 1231 e Petrus Roderici e Martinus Iohannis como monxes en 1231. Velascus aparece como vestiario en 1229 e en 1231, ó igual que Iohannes Campisinus como monxe. Nese ano de 1229 non temos constancia de que Gómez fose abade de Melón polos presentes documentos, pero si aparece como tal na bibliografía consultada ${ }^{4}$, polo que debemos supoñer que tamén estaban baixo a súa autoridade Fernandus Fernandi de Burgo como o seu vigairo e Ioanes de Hospicio como monxe.

Entre o 23 de xuño 1245 e 1256 temos a un novo don Pedro como abade de Melón, período durante o cal se realizan cinco cartas de foro, docs. 11, 13, 15, 16, 17; catro compravendas, docs. 18, 19, 20 e 21; e unha doazón no doc. 12. Xunto a el atopamos como priores Martinus en 1245 e 1250, e Petrus en 1252 e 1253; como subpriores Fernandus en 1245, 1250 e 1253, e Petrus en 1252; como chantre Gundisalvus en 1250 e 1253; como sochantre Rodericus en 1253; como enfermeiro Petrus en 1253; como celareiros Fernandus en 1252 e Monio en 1255; como vestiarios Fernandus en 1250 e Rodericus en 1252 e 1253; como monxes en 1245 Nunnus Petri, Arie e Pelagius, en 1246 Iohannes Petri e en 1250 Pelagius de Canis.

En abril de 1260 atopamos como abade de Melón a Fernando no doc. 22, e xunto a el unicamente a Nuno como celareiro.

Iohannes aparece como abade de Melón o 10 de xuño de 1264 realizando unha compravenda, con Fernando como monxe, doc. 23.

En 1274 cítase a frei Domingo como celareiro de Cans no doc. 24, pero descoñecemos o nome do abade naquel momento.

\footnotetext{
${ }^{4}$ LOSADA MELÉNDEZ, Mª J. e SOTO LAMAS, Mª T., "Oficios monásticos de Santa María de Melón”, 1169-1270, Boletín de Estudios del Seminario "Fontán-Sarmiento", n 13, 1992, pp. 26-28.
} 
O 15 de xuño de 1287 temos en solitario a don Pedro como abade de Melón realizando unha compravenda no doc. 26.

Estevo aparece como abade de Melón o 24 de xuño de 1288 realizando unha carta de foro no doc. 27, e xunto a el Juan Martinz como prior.

Entre o 29 de xullo de 1289 e o 3 de febreiro de 1297 exerce como abade de Melón don Pedro, docs. 28 e 31, tempo durante o cal se levan a cabo dúas contendas e dúas carta de foro. Baixo a súa autoridade atopamos a frei Rodrigo como monxe e procurador de Melón en 1292, doc. 29, ano no que non aparece explicitamente don Pedro como abade pero no que presupoñemos que continúa como tal, e o mesmo acontece en 1294 con frei Fernando e co celareiro frei Lourenço, doc. 30. En 1297 aparecen como prior frei Lourenço, como mestre dos frades Pedro Eans e como monxes Martin Moogo de Sageas, Pedro Aanz e Juhan Martinz?, antigo vestiario.

\section{Clero secular}

No tocante ó clero secular o máis destacado son dous bispos de Tui e outros dous de Ourense, xunto a outros cargos menores.

Estevo Exea cítase á fronte da diocese tudense en marzo de 1223 nos docs. 6 e 7. Xil Pérez de Cerveira aparece entre novembro de 1252 e o 10 de xuño de 1264 nos docs. 14, 15, 18, 19, 20, 21 e 23.

No tocante ós bispos de Ourense atopamos a Afonso o 25 de xuño de 1174, no doc. 1, e a Lourenzo entre o 19 de maio de 1231 e o 9 de xaneiro de 1233, nos docs. 9 e 10. Desta mesma diocese hai outros cargos menores: Alfonsus Michaelis e Ioanes Francum, antigos cóengos de Ourense e xuíces delegados do Papa en 1189, doc. 4; Martino Iohannis pertigueiro de Ourense en 1289 e Roderico Iohannis, crego do coro ourensá nese mesmo ano, doc. 28.

Por último atopamos a dous arquidiáconos de Baroncelle en 1189 no doc. 4, e 1289, no doc. 28, don V. Roderici e Roderico Roderici, respectivamente.

\section{Cargos cívico-militares}

No relativo ós cargos cívico-militares máis relevantes atopámonos cinco tenentes, tres meiriños e tres xuíces, xunto a outros cargos menores.

Como tenentes atopámonos en primeiro lugar a Fernando Ponce na Limia o 25 de xuño de 1174 , doc. 1, e do mesmo territorio entre o 19 de maio de 1231 e o 9 de xaneiro de 1233 temos conxuntamente a Paio Arias e a don Fernando Iohannis nos docs. 9 e 10, aparecendo este último xa en solitario como tenente de Toroño entre 1252 e o 10 de xuño de 1264 nos docs. 15, 18, 19, 20, 21 e 23. Baixo a autoridade deste último atopamos dous mordomos, Fernandus Faval en 
Toroño entre 1252 e 1256 nos docs. 15, 20 e 21, e Petro do Baal en Louriña entre 1255 e 1256, docs. 19 e 20, e dous celareiros de Toroño en 1253, Munio no doc. 16 e Martinus no doc. 17. En 1274 atopamos a última referenza a un tenente de Toroño, Xoán Fernández, no doc. 24. En marzo de 1223 atopamos a don Martín Sánchez nos docs. 6 e 7, como tenente de Turia (topónimo non localizado) e como tenente do castelo de Entenza, e xunto a el o seu mordomo Pelagio dos Ovos, doc. 7 .

En canto ós meiriños localizamos tres: Sanchi Pelagii o 9 de xaneiro de 1233 no doc. 10 e Munione Fernandi en 1252 no doc. 15 como meiriños rexios, e Rodericus Suariz como meiriño maior en Galicia o 2 de maio de 1255, doc. 19.

O 29 de xullo de 1229 atopamos a dous vigairos reais, Ioanes Laurentius e Rodericus Ioanis, e a un xuíz real, Gundisalvus Mendi, doc. 8. Esta última figura, a do xuíz, aparece novamente o 27 de outubro de 1292 con Fernan Soares, xuíz do rei en Toroño, e Miguel Martines chamado da Veiga, xuíz da terra de Louriña en representación do anterior, doc. 29.

No relativo ós cabaleiros unicamente se fai referencia a un o 15 de xuño de 1287, Juan Soarez, de Atios, no doc. 26.

\section{Escribáns e notarios}

No relativo ós escribáns atopamos na documentación consultada un total de nove. En primeiro lugar a Martín o 25 de xuño de 1174 e en 1181, docs. 1 e 2, que ó mesmo tempo é abade de Melón. Posteriormente atopamos a Arias en 1185 no doc. 3, a Ioannes de Atenis en agosto de 1219 no doc. 5, a A. en marzo de 1223 no doc. 7, a Gregorius o 19 de maio de 1231 no doc. 9, a Pelagius o 9 e xaneiro de 1233 no doc. 10, a Didacus Didaci o 23 de xuño de 1245 no doc. 11, a Iohannes en marzo de 1250, en novembro de 1252, en 1253 e o 1 de febreiro de 1255 nos docs. 13, 14, 16, 17 e 18, e por último a Petrus en 1252 no doc. 15.

En canto ós notarios e subnotarios, tanto de Toroño como das terras menores (especialmente Louriña) aparecen un total de trece. O primeiro que atopamos é Ioannes de Anote o 24 de febreiro de 1189, quen asina simplemente como notarius, aparecendo nese mesmo ano Ioannes Ferdinandi como notario do rei en Toroño no doc. 4. Tamén de Toroño é notario real Bernal Eans en 1252, doc. 15 , cargo que non volve a aparecer ata o 3 de febreiro de 1297 da man de Johan Perez no doc. 31, sendo a gran maioría dos notarios atopados da terra de Louriña. Así, aparecen como notarios desta terra Johannes Peres en 1252 no doc. 15, Iohannes Iohanni entre o 2 de maio de 1255 e 1256 nos docs. 19-21, Martinus Iohannis en abril de 1260 (onde aparece simplemente como notarii) e o 10 de xuño de 1264, docs. 22 e 23, acompañado nese último ano do subnotario xurado Rodericus Martini. Pedro Martinz aparece como notario xurado en terra de 
Louriña en abril de 1260, o 15 de xuño de 1287 e o 3 de febreiro de 1297 nos docs. 22, 26 e 31, e en 1274 aparece Gonzalvo Lopes como tenente de Pedro Calzado, notario publico en terra de Entenza e de Louriña, doc. 24. O 26 de abril de 1286 aparece Fernando Martinz como notario xurado en terra de Louriña, doc. 25 , e o 27 de outubro de 1292 e o 31 de xaneiro de 1294 o último notario nesta mesma terra que atopamos na documentación consultada, Johan Perez nos docs. 29 e 30, quen como xa indicamos anteriormente aparecerá como notario de Toroño en 1297. Por último aparece como notario público de Ourense Iohannes Martini o 29 de xullo de 1289 no doc. 28.

Cabe sinalar que con respecto ós documentos monásticos e ós escribáns, se non se indica o contrario, presupoñemos que se trata de monxes do propio mosteiro. No caso de que se especifique que se trata de notarios estes serían laicos.

\section{CRITERIOS DE TRANSCRIPCIÓN}

Por regra xeral séguense os criterios adoptados pola "Escuela de Estudios Medievales del Consejo Superior de Investigaciones Científicas (CSIC)", adaptándoas ás "Normes internationales pour l'edition des documents medievaux" e ás características específicas dos documentos escritos en galego.

Os documentos poden atoparse en forma de orixinais ou de copias, escollendo sempre para a transcripción o orixinal e apoiándonos nas copias do tumbo cando sexa necesario. Nos casos nos que o orixinal non foi localizado unicamente podemos acudir ás copias.

\section{Criterios de edición da colección documental}

Os documentos ordénanse cronoloxicamente. Tódolos documentos levan un número correlativo de orde, en cifras arábigas, en negritas. Tódalas referencias ó documento fanse a este número. En liña inferior á do número, ó lado esquerdo, exprésase, por esta orde, o ano, o mes e o día conforme ó sistema actual de computa-lo tempo. Se o documento dá o lugar e a redacción do mesmo, indícase polo nome actual.

\footnotetext{
${ }^{5}$ Véxase Normas de transcripción y edición de textos y documentos, Madrid, Escuela de Estudios Medievales, CSIC, 1944.

${ }^{6}$ Véxase Commission Internationale de Diplomatique et Commission Internationale de Sigillographie, Diplomatica et Sigillographica: travaux préliminaires de la Commission Internationale de Diplomatique et de la Commission Internationale de Sigillographie: pour une normalisation internationale des éditions de documents et un Vocabulaire international de la Diplomatique et de la Sigillographie, Zaragoza, Cátedra Zurita de la Institución Fernando el Católico, d.1. 1984 (Folia Caesaraugustana, 1).
} 
Debaixo da data, en cursiva, colócase un breve extracto, o rexesto do documento, adaptándose sempre que sexa posible o vocabulario, antropónimos e topónimos a formas actuais e así plenamente intelixibles e máis asequibles.

Debaixo do rexesto, en tamaño de fonte menor ó do texto, figuran os datos catalográficos onde se indica o pergameo ou tumbo utilizados: cítase, en primeiro lugar e en maiúsculas, a ubicación física dos exemplares; seguen as siglas do arquivo en maiúsculas cursivas; a continuación indícase se se trata dun pergameo orixinal ou dunha copia simple. As referencias a catálogos indícanse con "Catálogo". O texto edítase en letra redonda, no mesmo tamaño que o rexesto.

\section{Regras xerais de transcripción: lectura}

As transcripcións tratáronse de facer respectando no posible as peculiaridades do manuscrito. Como norma xeral respectouse a súa ortografía. En consecuencia, mantívose a $c$, o uso indebido das letras $b$ por $v, b$ por $p, y$ por $i$ ou viceversa, e os restantes casos, así como a omisión ou inclusión de letras e cantas alteracións se atopen.

A $i$ con valor de vogal transcríbese sempre $i$, nunca $i$ larga o $j$. Nos textos latinos ponse $i$ en lugar de $j$. Polo contrario, a "i" longa ante vogal, transcríbese por $j$ nos textos en galego. A $u$ e a $v$, empregadas indistintamente como vogais ou consoantes, transcríbense conforme ó seu valor fonético, prescindindo da forma en que aparecen no manuscrito. As letras dobres en principio de palabra transcríbense como simples, mentres que as letras dobres en medio de palabra respéctanse.

Os números reprodúcense en cifras romanas, tal e como aparecen nos documentos, transcribíndose do xeito no que aparezan no orixinal, pero sempre en maiúsculas. Con respecto ás datas, suprímese o punto inicial e o final, conservándose os puntos entre as cantidades.

Ademais destas regras xerais de transcripción sinalaremos os signos notariais en cursiva ou cunha cruz entre parénteses $(+)$. As grafías aberrantes ou destacables serán sinaladas en letras cursivas seguidas dun (sic).

\section{Abreviaturas e siglas}

Tódalas abreviaturas e siglas resólvense sen necesidade de indica-las letras suplidas, e só en caso de dúbida se indica en letra cursiva. Os signos de "\&", e " " (tironiano) transcríbense por et. "Po" transcríbese por Pedro. O signo “ " (en latín "cum-" en principio ou en medio de palabra; "-us" en final de palabra), en galego transcríbese, respectivamente, por con-e -os.

No tocante ós guións sobre vogais que indiquen a abreviatura dunha nasal en palabras que rematen en "s" decidiuse resolvelo coa terminación "ns" (Caens). O "guión sobre n" transcríbese por $n n$-dobre n-, e non pola letra "ñ". Por outra banda, no caso da preposición "en” seguida de artigo, procédese á súa separación en $o$. 


\section{Ortografía}

Como norma xeral respéctase sempre a ortografía do manuscrito. $\mathrm{Na}$ transcripción sepáranse as palabras que no orixinal estean unidas, e se unen as letras ou sílabas dunha mesma palabra que aparezan separadas. As contraccións de palabras respéctanse. No caso de que a preposición "de" apareza unida a unha palabra que comece por vogal transcribiranse separándoas cun apóstrofo ( $\mathrm{d}^{\prime}$ ).

As maiúsculas e minúsculas, independentemente do uso que faga delas o orixinal, empréganse conforme á ortografía moderna. Os signos de puntuación, no caso de que os haxa, son suplidos polos actuais. Non se empregan acentos nin tiles. As palabras textuais que se din ou se atribúen a algunha persoa reprodúcense entre comillas.

Utilízase punto e aparte para a separación das cláusulas de sancións, data, testemuñas, etc. Nos documentos máis longos tamén se empregan puntos e aparte para alixera-la súa lectura e facilita-la súa comprensión.

\section{Manuscritos ou fragmentos defectuosos}

Cando un manuscrito está en mal estado, ó transcribilo séguense as normas xerais citadas, pero de xeito que na transcripción quede patente o seu estado, facendo as aclaracións e poñendo as notas que se xulguen necesarias. As letras dubidosas ou tan imperfectas que sen o contexto poderían interpretarse de diferentes xeitos, transcríbense en cursiva seguidas dun interrogante.

En canto ás restitucións do texto, no caso de que no orixinal existan lagoas, acódese á copia do tumbo e transcríbese entre corchetes [ ]. As lagoas non restituíbles do texto indícanse con puntos suspensivos entre corchetes rectos: [...]. As adicións, é dicir, as lagoas cubertas por nós, indispensables para entende-lo sentido do texto, móstranse entre corchetes agudos: $<>$. En canto ás adicións interlineares no manuscrito trascríbense entre barras oblicuas e de sentido contrario: $\backslash /$. 
SigLAS E ABREVIATURAS

ACO.- Arquivo da Catedral de Ourense

AHN.- Archivo Histórico Nacional

doc. ou docs.- documento ou documentos

fol. ou fols.- folio o folios

n. ${ }^{\circ}$ ou n. ${ }^{\text {os }}$.- número ou números

orix.- orixinal

OU.- Ourense

p. ou pp.- páxina ou páxinas

perg.- pergameo

PO.- Pontevedra

...r.- ... recto

...v.- ... volto

\section{FONTES MANUSCRITAS}

I. Arquivo da Catedral de Ourense

Fondo Pergameos. Mosteiro de Melón.

Sinaturas:

651: Doc. n. ${ }^{\circ} 13$.

681: Doc. n. ${ }^{\circ} 15$.

686: Doc. n. ${ }^{\circ} 18$.

II. ARQuivo HistóRICO NACIONAL

\section{II.1. Sección Clero (Fondo Monástico).}

Serie Pergameos. Mosteiro de Melón. Carpetas:

1438/11:Doc. n. ${ }^{\circ} 2$.

1440/1: Doc. n. ${ }^{\circ} 6$.

1440/2: Doc. n. ${ }^{\circ} 7$.

1441/3: Doc. n. ${ }^{\circ} 9$.

1441/9: Doc. n. ${ }^{\circ} 10$.

1444/17: Doc. n. ${ }^{\circ} 12$.

1446/16: Doc. n. ${ }^{\circ} 16$.

1446/17: Doc. n. ${ }^{\circ} 17$.

1447/20: Doc. n. ${ }^{\circ} 19$.

1448/7: Doc. n. ${ }^{\circ} 20$.

1448/11: Doc. n. ${ }^{\circ} 21$. 
1450/16: Doc. n. ${ }^{\circ} 23$.

1454/15: Doc. n. ${ }^{\circ} 28$.

1455/8: Doc. n. ${ }^{\circ} 29$.

1455/12: Doc. n. ${ }^{\circ} 30$.

1456/5: Doc. n. ${ }^{\circ} 31$.

II.2. Sección Códices. Mosteiro de Melón. Tumbo n. ${ }^{\circ}$ 325-B

fols. 360 v. e 361 r.: Doc. n. ${ }^{\circ} 27$.

fol. 364 r: Doc. n. ${ }^{\circ} 22$.

fol. 365 r. e v.: Doc. n. ${ }^{\circ} 11$.

fols. 365 v. e 366 r.: Doc. n. ${ }^{\circ} 14$.

fol. 366 r.: Doc. n. ${ }^{\circ} 25$.

fols. 366 v. e 367 r: Doc. n. ${ }^{\circ} 24$.

fol. 370 r. e v.: Doc. n. ${ }^{\circ} 3$.

fol. 371 v.: Doc. n. ${ }^{\circ} 26$.

fols. 372 v. e 373 r.: Doc. n. ${ }^{\circ} 5$.

fol. 383 r. e v.: Doc. n. ${ }^{\circ} 4$.

fol. 391 r.: Doc. n. ${ }^{\circ} 1$.

fols. 393 v. e 394 r.: Doc. n. ${ }^{\circ} 8$.

\section{CATÁlogos}

LEIRÓS FERNÁNDEZ, Emilio, Catálogo de los pergaminos monacales del Archivo de la S. I. Catedral de Orense, Santiago, El Eco Franciscano; Dirección General de Archivos y Bibliotecas, 1951 (Bibliotecas y Archivos Eclesiásticos, 1).

ARCHIVO HISTÓRICO NACIONAL, Catálogo de Pergaminos Monásticos Gallegos de las Provincias de Coruña, Orense y Pontevedra.

\section{COLECCIÓN DiPLOMÁTICA}

1174, xuño, 25

Don Mendo Abade, a súa muller dona Urraca e os seus fillos Pedro, Xoán, Velasco e dona

Maior doan ó mosteiro de Santa María de Melón a herdade de Pereiras.

MADRID, $A H N$, Fondo monástico, Melón, Tumbo n. ${ }^{\circ}$ 325-B, fol. 391 r., copia simple.

In nomine Domini nostri Iesuchristi, amen. Inter cetera virtutum et misericordie opera elemosina maxime comendatur, dicente Domino, date elemosina et ecce omnia munda sunt vobis; et alibii conclude elemosinam in sinu pauperis et ipsa pro te exorabit. Propter ea ego domnus Menendus Abbas $^{7}$ una cum uxore mea domna Urraca necnon et cum filiis et filiabus meis, Petro, scilicet, Ioane, Velasco et domna Maiore, do Deo et Sancte Marie de Melon, et 
abbati et fratribus tam presentibus quam futuris ibidem Deo servientibus, hereditatem de Pereiras, pro remedio animarum nostrarum et parentum nostrorum, cum terminis suis antiquiis, cum pratis, cum aquis, cum arboribus et cum omnibus directuris suis per ubicumque eam invenire potuerint. Ita ex hac die habeant, possideant, vendant et cambient et faciant ex ea quod voluerint.

Si quis igitur hoc meum voluntarium factum tam ex meo genere quam ex alieno irrumpere temptaverit, sit maledictus et excommunicatus et cum Iuda traditore Domini in inferno damnatus, et pro tanto excessu pariat voci monasterii pulsanti quingentos marabitinos et hereditate duplata.

Facta carta donationis VII kalendas iulii, regnante Domino rege Fernando, era M.CC.X.II. In sede auriensi Adefonso episcopo, tenente Limia Fernando Pontio.

Factum est hoc in manu domini Martini abbatis.

Martinus (signo: roboramus) qui notavit.

1181

Paio Peláez de Atios e a súa muller María Pérez ceden pola súa alma ó mosteiro de Melón as herdades que teñen en Barbetha e Cristovail por oitenta e cinco soldos, coa opción de recuperala antes da súa morte, momento no cal pasará a poder do mosteiro.

MADRID, $A H N$, 1438/11.- Perg. orixinal, 240x11 mm. Latín, gótica documental caligrafiada.

MADRID, $A H N$, Fondo monástico, Melón, Tumbo n. ${ }^{\circ} 325-\mathrm{B}$, fol. 367 r., copia simple.

Era $M^{a}$.CC ${ }^{a}$.XVIIII ${ }^{a}$. Ego Pelagius Pelaiz de Athenus una cum consilio uxoris mee scilicet Maria Petriz necnon et cum filiis et filiabus meis mitto impignore abbati et fratribus de Melon quicquid habeo in Barvetha et in Cristovail tali pro octaginta $\backslash \mathrm{V}^{\mathrm{e}}$ solidos tali pacto ut semper fratres eam habeant et possideant, excepto si eam ego in vita mea voluero redimere, potestatem habeam redimendi, ita tamen ut ad mortem meam hereditas remaneat monasterio pro anima mea. Post mortem vero meam nullus habeat potestatem eam ulterius redimendi set firma et rata maneat monasterio.

Factum est hoc in concilium et per testes qui presentes fuerunt: Petrus testis et confirmans. - Suerius testis et confirmans. - Nunus testis et confirmans.

Martinus qui notuit ${ }^{8}$.

\footnotetext{
${ }^{7}$ Probablemente Abbas sexa unha mala lectura do amanuense.

${ }^{8}$ Notuit: escrito en xeroglífico.
} 
1185

Escritura pola cal o mosteiro de Melón obtén de diversos veciños diferentes propiedades no monte de Cans, en Donicoes, en Veron e en Cristovail.

MADRID, AHN, Fondo monástico, Melón, Tumbo n. ${ }^{\circ} 325-\mathrm{B}$, fol. 370 r. e v., copia simple.

Ego Martinus abbas de Melone per Dei gratiam, notum fieri volo presentibus et futuris quod scriptum est in carta ista: Gomez Crispus misit nobis in pignore quidquid habebat in monte de Canales per XXXII soldos et una bone precii XVIII solidis, et fiunt quinquaginta; postea vero dedimus ei pro eodem pignuo decem et VI solidos.

Testes Rodericus et Martinus, testis, germanus eius.

Arias scripsit.

Ego domnus Martinus abbas de Melon una cum fratribus meis do tibi Alvaro Diaz de Barro unum bobem apreciatum in tredecim solidis quem tu recepisti pro docem solidis, quia fecisti ob amorem decem solidos, pro quo dedisti nobis hereditatem quam habes in Dunicoes et Ique has in Veron, ut habeamus/ et possideamus eam $\mathrm{a}<\mathrm{b}>$ sque ulla contraditione filiorum et fratrum tuorum sciendum etiam quod omnibus quod dedimus tibi super hoc quinque solidos et una inter panem et fabas [...] et vendebat in illo tempore talega XII denarios.

Factun lest/ hoc coran multis testibus qui ibi presentes fuerunt: Nunnus testis, N. testis, Nunus testis, Petrus testis.

Notum omnibus tam presentibus quam futuris quod ego domnus Martinus abbas de Melon dedi Fernando Petriz filio de Pelagio Martinizi IV solidos Ipartem/ suam quantam habeo in Cristovail, et quando dederit mihi solidos meos recipiet hereditatem suam.

In nomine Domini amen. Notum omnibus quod ego Nudu Midiz cum uxore mea et filiis facimus cartulam venditionis de hereditate mea ipsa quam habeo de avorum meorum progenie in Cristovail vobis domino Martino abbati de Melon pro pretio que a vobis recepi, scilicet, unum bobem per quatuordecim solidis, quod mihi et vobis bene complacuit, et nihil de pretio remansit apud vos, et ab hac die sit hereditas de iuri meo abrasa et iuri vestro tradita.

$\mathrm{Si}$ vero aliquis homo tam de meo genere quam de alieno hanc meam voluntariam venditionem infringere tentaverit, iram Dei omnipotentis incurrat, et pro tanto excessu pariat vobis thereditatem/ duplatam.

Et factum est hoc era M.CC.XX.III.

Qui presentes fuerunt Petrus testis, Pelagius testis, Ioanes testis, Nunus testis (+).

Notum sit omnibus quod ego Petrus Coronatus mito in pignore abbati et fratribus de Melon quidquid habeo ex parte mea et germanorum meorum, et partem de domino Petro Crispo in Cristobail per unum bobem apretiatum in undecim solidos, tali convenientia quod si aliquis eam calumniaverit, ego eam semper defendam. Et propter hoc dedi fratri Afonso Petriz de Molin excepto quod si partem de dicto Petro Crispo non potuero defendere, debebo dare medietatem de supranominato precio.

Ego dominus Martinus abas de Melon dedi Martino Petriz Alcrebado unum poldrum pro $\mathrm{V}$ maraveditinos et quinque solidos et suo cognato Roderigus Bacicryz unum bobem pro tres maravidinis et alio eius cognato Ioane Gomez Camundu tredecim solidos pro quantum ipsi habebant in montem de Canales quod ego teneban ab avunculo suo Sueri Nigret. Feci hoc tali 
AS PARROQUIAS DO PORRIÑO, CANS E ATIOS NA DOCUMENTACIÓN DO

pacto si ego potuero habiere Suerius Nigret ad otorgandum, dent michi supra nominatos decem moravitinis.

1189, febreiro, 24.- Atios.

Carta de poder dada por Lourenzo Ioanis, crego reitor de Santa Eulalia de Atios, a don Pedro, abade de Melón, e ós frades Lourenzo Martínez e Pedro Ioannis, na causa que teñen contra Martín Moogo dito Guerra, reitor de Santa María de Sanguiñeda, pola metade do décimo do couto de Cans.

MADRID, AHN, Fondo monástico, Melón, Tumbo n. ${ }^{\circ} 325-\mathrm{B}$, fol. 383 r. e v., copia simple.

Noverint universi quod ego Lourentius Ioanis \clericus/ rector ecclesie Sante Eulalie de Ateos tudensis diocesis, nomine ipsius ecclesie, constituo et ordino procuratores meos sindicos et autores religiosum virum domnum Petrum abbatem monasterii Sante Marie de Mellon et fratres Laurentium Martini et Petrum Ioannis, monachos ipsius monasterii, exibitores presentium unumquemque eorum insolidum, ita quod non sit melior conditio ocupatis in causa que vertitun vel verti spectatur inter ipsum abbatem supradictum, ex une parte et Martinum Moogo dictum Guerra, rectorem Sante Marie de Sangineda ex altera super medietatem quarundam decimarum in cauto de Canalibus spectantium ad ecclesiam de Ateos supradictam. Que medietas supradictarum decimarum per dominum abbatem supradictum nomine monasterii supradicti per quamdam compositionen factam inter ipsum monasterium et ecclesiam supradictam, et similiter super alia medietate dictarum decimarum que pertinent ad ecclesiam supradictam de Ateos, secundum quod continet in supradicta compositione.

Que compositio fuit facta per venerabilem dominum V. quondam cantorem et Alfonsum Michaelis et Ioanem Francum quondan canonicos auriensis, iudices delegatos a Domino Papa inter monasterium et ecclesiam supradictam coram venerabile viro domno V. Roderici archidiacono de Baroncelle in ecclesia auriensi coram alio iudice ab eo dato vel dando $a b$ agnoscendum, defendendum, excipiendum, replicandum, proponendum, respondendum, suplicandum inter contestandum iuramentum de calumnia seu de veritate dicenda perpetrandum, et alterius cuiuslibet generis sacramentum, et ad omnia alia et singula faciendum quam verus et legitimus potest facere procurator, et quod ego facerem [potuere] si personaliter presens fuissem. Do tibi et concedo eiusden vel eundem procuratoribus vel procuratori plenam et liberam potestatem; procuratorem vel procuratores, unum vel plures constituendi vel substituendi vel destituendi eosdem et in se procuratoris oficium resumendi quandocumque et quotiescumque sibi audebitur expedire. Ratum et firmum perpetuo habentes quidquid cum predictis vel pro dicto procuratoribus vel procuratore constitutum vel constitutos substitutum vel substitutos ab eisdem vel ab eodem autum fuerit, sive contra procuratum, relevantes eos vel eum constitutos vel constitum substitutos, vel substitutum ab ipsis vel ab ipso ab omni onere facisdandi, et de iudicato solvendo si necesse fuerit sub hipoteca rerum mearum, permitens contra pro eiisdem in cuius rei testimonium ego supradictus Laurentius Ioannis rogavi Ioannem Ferdinandi notario Domini regis in Torono quod faceres inde sibi hoc publicum ratum instrumentum.

Qui presentes fuerunt: Ioannes monachi de Sancta Marta, Ferdinandus Agustin, Nuno Fernandez, Ioanes Petri, Ferdinandus Nuni et alii multi. Datum apud ecclesiam supradictam de Ateos, VI calendas marcii era M.CC.XX.VII. 
Ego vero Ioannes de Anote notarius supradictus presens fui et per mandatum supradicti Laurenti Ioannis hoc perentoriam, manu propia scripsi et signum meum aposui quod tale est in testimonium veritatis $(+)$.

1219, agosto

Acordo entre Pedro Albo e o seu fillo Pedro Pérez co mosteiro de Melón sobre a herdade que estes teñen no lugar de Liñar de Gunda no termo de Cans.

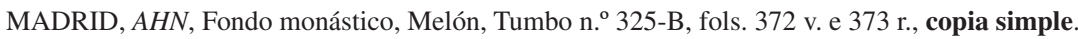

Era M.CC.L.VII, mense agusti. Notum sit cuntis presentibus et futuris quod nos Petrus Alvus clericus de Santa Marta et filii eius Petrus Petri et Nunus Petri facimus pactum et placitum cum fratre Petro abbate de Melon et cum conventu eiusdem de ipsa nostra hereditate quam habemus in termino de Canalibus in loco qui dicitur Linar de Gunda, scilicet, quod nos supra nominati Petrus Alvus et filii mei debemus plantare ipsam hereditatem et omnes qui ibi habitaverit sint vassali de abate et de conventu de Melon et facere locum de vocibus et de calumnis et de omnibus que pertinent vel pertinere debent voci regis sicut et allii qui habitant in Canalibus et medietatem decimarum et illam (sic) conventus debent defendere ipsos homines ad directum. Et nos abbas et conventus damus vobis Petro Albo et filio vestro Petri Petri multa vestra tantum portionem taxata de ipsa plantatione popter ${ }^{9}$ homicidium et illarum quatuor quas Dominus rex letuar ${ }^{10}$ (sic) sibi in allis locis que si ibi facte fuerint partamus $^{11}$ eas per medium in vita nostra tantum, et ad obitum amborum in pace remaneant omnia que ad vocem regalium pertinent monasterios. Et nos donus Petrus Albus et filius meus Petrus Petri propter amorem istum quod nobis facit dominus abbas debemus facere vobis servitium propter hoc.

Et qui hoc pactum fregerit alteri parti pectet quinquaginta marabitinos placitum autem in suo robore permaneat.

Qui presentes fuerunt: Petrus prior, Fernandus Cabus, Fernandus cellerarius, Fernandus Arie frater $<$ a $>$ potegarius, Rodericus vestiarius, Ioannes infirmarius, Rodericus Martini contralorum (sic), Petrus sacrista, Fernandus Petri de Medes.

Ioannes de Atenis qui notavit per mandatum Petri Albi et fili eius Petrus Petri.

\section{6}

1223, marzo, 29

Urraca Gómez véndelle ó mosteiro de Melón as súas herdades de Arnoso, de Arais e de San Lourenzo, por cen soldos.

MADRID, $A H N$, 1440/1.- Perg. orixinal, 380x60 mm. Latín, minúscula diplomática.

MADRID, AHN, Fondo monástico, Melón, Tumbo n. ${ }^{\circ} 325-\mathrm{B}$, fols. 373 v. e 374 r., copia simple.

\footnotetext{
${ }^{9}$ Non aparece escrito propter, pero polo que lemos o sentido debería ser este.

${ }^{10}$ Probablemente o amanuense non soubo ler esta palabra.

${ }^{11}$ O amanuense escribe sorciamus, pero a locución per medium leva a pensar que no orixinal dicía partamus.
} 
AS PARROQUIAS DO PORRIÑO, CANS E ATIOS NA DOCUMENTACIÓN DO MOSTEIRO CISTERCIENSE DE SANTA MARÍA DE MELÓN. SÉCULOS XII E XIII

In Dei nomine. Ego Urraca Gomit facio cartam in centum aureis roboratam vobis domno Vermudo abbati de Melon et Gomecio priori et conventui de omni hereditate quam habeo in Arnusu et in Sancto Laurentio vel debeo habere ego et omnis vox mea. Et vos ${ }^{12}$ datis mihi pro illa precium nobis et vobis placitum, scilicet $\mathrm{C}$ solidos et pro robore solidum $\mathrm{I}^{\circ}$. Exhinc habeatis illam, possideatis et velle vestrum de illa faciatis.

Et quicumque propinquus vel extraneus contra hanc cartam venerit, pariat vobis hereditatem duplatam vel triplatam et voci regis $\mathrm{C}$ aureos persolvat.

Facta carta sub era $\mathrm{M}^{\mathrm{a}}$.CC ${ }^{\mathrm{a}}$. $\mathrm{LX}^{\mathrm{a}}$.I et quot $\mathrm{IIII}^{\text {or }}$ kalendas aprilis.

Et ego Urraca Gomit in hac carta manus meas roboro, concedo et confirmo quod in eternum maneat valitura.

De omni hereditate vobis vendita tam in Arnusu quam in Arais vel in Sancto Laurentio, quantum habeo, in iure vestro maneat sine omni calumpnia.

Qui presentes fuerunt: Gomecius prior et frater Fernandus subprior.

Petrus Ramirit portarius.- Petrus subinfirmarius.- Michael apotacarius.

Menendus Arie, monachus.- De conversis: Arias Garcie.- Frater Fernandus Munionis.

De clericis: Iulianus prebi ${ }^{13}$ presbiter de Tauviga.- Petrus Guiladi.- Arias presbiter de Urgillum.- Martinus Froile miles.

Regnante in Legione Domino rege Aldefonso, in Tuda Stephano episcopo, tenente Turiam domno Martino Sancii ${ }^{14}$.

1223, marzo

Pedro Albo compra a varios veciños diferentes propiedades en Liñar de Gunda.

MADRID, $A H N$, 1440/2.- Perg. orixinal., 380x130 mm. Latín, gótica documental.

MADRID, $A H N$, Fondo monástico, Melón, Tumbo n. ${ }^{\circ} 325-\mathrm{B}$, fol. 372 r. e v., copia simple.

In Dei nomine. Notum sit omnibus tam presentibus quam futuris quod ego Goncalvus quid venit et Petrus Pelagii et Maria Pelagii et Maior Pelagii et Salvator Pelagii et Garcia Pelagii et Orrace Pelagii et Sancia Pelagii et filios de Symeon Alvarz, tibi Petrus Alvo facimus cartam firmissimam de nostra hereditate quod habemus in loco nominato Linar de Gundia cum tota sua voce. Damus tibi quantum ibi habemus ad monte et fonte pro precio quod de vobis accepimus. In primiter, tenuistis illa in pignore pro $\mathrm{C}^{\mathrm{m}}$ solidis et desuper comparastis illa de nobis et dedistis ad Gonzalvus quod venit X solidos et in robore I vaso de mel, et Mendus Salvatoriz fideiussor quod amparet vos cum illa; ad Petrus Pelagii $\mathrm{X}$ solidos et in robore I vaso de vino; ad Maria Pelagii X solidos et in robore I

\footnotetext{
${ }^{12}$ Vos: Realmente o amanuense escribiu vox; despois corrixiuno poñendo unha $\mathrm{s}$ recta sobre a $\mathrm{x}$.

${ }^{13}$ Previ: Escrito con $\mathrm{p}$ con guión enriba. Dado que a transcrición destas tres letras $(\mathrm{p}, \mathrm{b}, \mathrm{i})$ non ten sentido, debe atribuírse a un erro do amanuense que quizais comezou a escribir presbiter.

${ }^{14}$ Tenente Turiam domno Martino Sancii: o topónimo Turiam non se localizou. Por outra banda consta que domno Martino Sancii exerceu de tenente de Toroño e de Ribadavia (Limia, Montenegro, Monterroso e S. Xoán de Penacorneira), así mesmo foi alférez do rei entre 1218 e 1226. (Véxase ROMANÍ MARTíNEZ, M., A Colección Diplomática do Mosteiro Cisterciense de Santa María de Oseira, vol. II, Santiago, 1989, pp. 1309, 1329 e 1330, dentro dos apartados de alféreces e de tenentes de Ribadavia e de Toroño),
} 
candelabr[um]; ad Maior Pelagii X solidos et in robore I calabaca de vino; ad Salvator Pelagii X solidos et in robore I colmena; ad Garsia Pelagii L ${ }^{a}$ et IIII ${ }^{\text {or }}$ solidos pro suo quinione et de Suerio Pelagii et de Iohanne Pelagii et de Pelagio Pelagii et de Orrace Pelagii, et desuper fideiussor Menendus Salvatoriz per se et per sua voce quod amparet semper cum illa, et in robore II solidos et IIII denarios. Ego Pelagio Fernandiz nominato $\mathrm{N}[\ldots .$.$] bos tibi Petrus Albo vendo meo quinione et de meos fratres de ipsa hereditate pro V$ solidis et in robore I vaso de vino, et fideiussor Pelagio Maraniom; ego Sancia Pelagii una cum fratres meos tibi Petrus Albus vendimus nostros quiniones de ipsa hereditate pro $\mathrm{X}$ solidis, et in robore una bona cena et sic completum est totum. Habeatis vos et voci vestre in secula seculorum.

Si quis homo venerit vel venerimus de nostra parte vel de extranea contra hanc vendictionem nostram ad irrumpendum venerit, pectet vobis vel voci vestre ipsa hereditate duplata, et domino terre $\mathrm{M}^{\mathrm{e}}$ morabitinos pectet.

Facta carta in tempore rege Domino Alfonso regnante in Legionem et in Asturias et in Gallecia, episcopus in Tuda domnus Stephanus, tenente castello Antencia domno Martino Sancii, maiordomus Pelagio dos Ovos.

Sub era $M^{a} \cdot C C^{a} \cdot{ }^{a} X^{a} \cdot I^{a}$ mense marcii. Qui presentes fuerunt: Petrus testis, Pelagius testis, Iohannes testis et alii multi quid viderunt et audierunt. A. scripsit et hoc signum feci (+).

Ego $^{15}$ Gondissalvo Pelagii de Lira vendo meo quinione et de Ruderico Pelagii tibi Petro Albo, vendo mea hereditate quanta nos habemus in Linare de Gunda pro XII solidis et medio, et in robore $\mathrm{I}^{\mathrm{a}}$ cabaacia de vino; ego Martino Pelagii vendo meo quinione quanta ego ibi habeo in Linare pro $\mathrm{X}$ solidis, et in robore $\mathrm{I}^{\mathrm{m}}$ vasum de vino; et filios de Rama Pelagii quanta ibi habent pro $\mathrm{X}$ solidis, et in robore $\mathrm{I}^{\mathrm{o}}$ vaso de vino des Porto pa la canio? quomodo corri per aqua pecdeyra (sic) adsi quomodo vadit ad rio de Lor et di parte per termino de Sancta Marta et per termino de Cays. Ego Menendo Pelagii vendo meo quinione quanta ego ibi habeo pro $\mathrm{X}$ solidis, et in robore $\mathrm{I}^{\mathrm{a}}$ cabaacia de vino.

1229, xullo, 29

Contenda entre o mosteiro de Melón e Exidio Pérez sobre unhas propiedades na herdade de Pereiras, que se resolve entregando Exidio as propiedades discutidas ó mosteiro.

MADRID, AHN, Fondo monástico, Melón, Tumbo n. o. 325-B, fols. 393 v. e 394 r., copia simple.

Horta fuit dissensio inter abbatem de Melon et inter Egidium Petri predictas (sic) super hereditatem de Perariis scilicet super tertiam de quinta ipsius hereditatis et super duas vineas quod sunt ex parte nostri casalis et super duos forarios Petrum Arie et Ioanem Arie et hoc dictum est quod domnus abbas et Egidius Petri miles de mandato Ruderici Ioanis vicarii regis ante iudicem regis Gundisalvum Mendi aparuerunt et pars domni abbatis coram iudice hereditatem supradictam petiit et tunc pars infraescriptis? dixit quod non erat paratus respondere sibi quem non habebat advocatum nec vicarium et [ilexible] petiit inducias ut haberet consilium super his cum iudex et iudex dedit illi inducias usque in spatium novem dierum ut veniret paratus cum advocato suo et cum vicario eam faciendi

\footnotetext{
15 A partires de aquí o documento está escrito por outro amanuense cuxa escritura é de menor calidade cá do escribán anterior.
} 
AS PARROQUIAS DO PORRIÑO, CANS E ATIOS NA DOCUMENTACIÓN DO MOSTEIRO CISTERCIENSE DE SANTA MARÍA DE MELÓN. SÉCULOS XII E XIII

directum abbati sive eius parti et abbas similiter ei et in eodem die quem nobis asignaverat iudex uterque venit et coram iudice utraque pars spontanea voluntate potuerunt sibi vicarios. Abbas scilicet posuit Fernandum Fernandi de Burgo, domno Egidius posuit Ioanem Fernandi militem de Avelanedo. Tunc pars abbatis petiit hereditatem supradicta cum suo directo, et miles respondit sic: "ignoro quod petitis et hereditatem istam non cognosco vobis". Hoc audito iudex iudicavit utrique parti quod venirent usque ad novem dies in eadem hereditate et essent ibi parati cum vicariis suis et cum apreciatoribus suis et cum fideiusoribus et abbas predictus determinaret hereditates quas petebat et dicti apreciatores apreciarent hereditatem qua pedetenti? determinaverat et domnus Egidius daret fideiusores pro precio hereditatis ut essent apreciatas apretiatione et quod abbas daret fideiusorem ut cessaret de ista demanda et dederunt que partibus in [ilexible] fideiusores. Et ad predictum diem domnus abbas venit cum ambobus vicariis et cum apretiatoribus suis et cum fideiusoribus et ipse miles non venit neque aliquis pro eo qui satisfaceret nobis tunc abbas petiit vicario regis ius hereditatis et ipse respondit super hoc habebo consilium et item ivimus ad Rodericum Ioanis et narravimus sibi qualiter resgesta fuerat et ille misit nos in posesionem supradicte hereditatis et incautavit eam centum marabitinos.

Qui presentes fuerunt huius pacto: Menendus Alvari, Velascus Saccus, Rodericus Froile et Salvador Froile, Petrus Maurus de Portu, Ioanes Laurentius regis vicarius et ambo vicarii Ioanes Campisinus monachus, frater Ioanes de Hospicio, frater Munio Ianeiro, Ioanes Arie.

Qui presentes fuerunt quando recepimus hereditatem isti sunt: Velascus vestiarius, frater Ioanes de Hospicio, Velascus Saccus, Clemente, Ioanes Arie, Petrus Arie, Stefanus Fernandi miles, Ioanes Fernandi homo Roderici Ioanis qui integravit hereditatem supradictam Munioni Ianeiro, Ioanes Munionis de Laureiro.

Hoc fuit factum sub era M.CC.LX.VII et quot IV kallendas agusti (+).

1231, maio, 19

Os milites Exidio Pérez, coa súa esposa dona Inés, e Xoán Pérez, fillos do milite don Pedro Méndez dito Feyioo, venden ó abade e ó convento de Melón a herdade que teñen na vila de Pereiras, e renuncian a dous foros que o pai daqueles entregara a Melón.

MADRID, AHN, 1441/3.- Carta partida por a.b...m., perg. orixinal, 350x315 mm. Latín, gótica caligrafiada.

MADRID, AHN, Fondo monástico, Melón, Tumbo n. 325-B, fols. 391 r., v. e 392 r., copia simple.

A...B...M. In nomine Domini, amen. Notum sit omnibus presentibus et futuris per hoc scriptum perpetuo valiturum quod ego Egidius Petri miles, de consensu uxoris mee domne Eynes presentis et concedentis et ego Iohannes Petri miles filii videlicet domni Petri Menendi militis dicti Feyioo ambo pariter presenti scripto profitemur nos vendidisse vobis domno Gomecio abbati et conventui monasterii Sancte Marie de Melon et per vos eidem monasterio totam nostram hereditatem quam habem<us $>$ vel habere debemus in villa que vocatur Pereyras et in toto eiusdem ville termino, videlicet duas tercias de tota ipsa villa cum omnibus suis directuris minus una quinta quam vos iam in ipsis duabus terciis habebatis. Vendimus inquam vobis predictam hereditatem et accepimus a vobis pro illa duo milia CC et LX solidos quos statim nobis integre persolvistis. Nos preterea abbas et 
conventus supranominati damus vobis ipsam eandem hereditatem cum palumbare quod ibi vobiscum habemus tantum in vita vestra tenendam, nec liceat vobis ipsam hereditatem totam vel eius partem vendere vel obligare seu alio quolibet titulo alienare; damus etiam vobis similiter in vita vestra capones annuatim percipiendos quos nos percipere consuevimus ab ipsis nostris forariis; tenemur insuper ex presenti pactione dare vobis annuatim solidos quingentos in festo Sancti Iohannis Babtiste similiter in vita vestra; addicimus etiam nos predicti milites quod cum alterum ex nobis decedere contigerit, statim recipians vos partem [quo spe]ctat ad ipsum qui decesserit et possideatis perpetuo libere et in pace. Et non teneamini solvere superstiti annuatim nisi medietatem tantum [predictorum quingentorum] solidorum; superstite vero mortuo, habeatis vos totam ipsam hereditatem ab omni pensione liberam et absolutam et possideatis integre quicquid in prenominata villa et in eius termino ad nos spectare debet vel spectat iure hereditario in perpetuum; nos etiam tenemur ex pacto amparare vos s[emper] cum ipsa hereditate et defenderi ad directum.

Si quis igitur de nostra parte vel de extranea contra hanc venditionem vel contra condiciones appositas in hac carta venire presumpserit, iram Dei omnipotentis incurrat et pectet vobis vel successoribus vestris ipsam hereditatem duplatam et quantum in ea fuerit melioratum et pro temerario ausu parti regie mille morabitinos persolvat. Carta ista in suo robore nichilominus permanente.

Facta carta venditionis sub era $\mathrm{M}^{\mathrm{a}} \cdot \mathrm{CC}^{\mathrm{a}}$. $\mathrm{LX}^{\mathrm{a}}$.VIIII ${ }^{\mathrm{a}}$, XIIII ${ }^{\mathrm{o}}$ kalendas iunii, regnante in Legione et Castella rege Domino Fernando, episcopo in Auria domno Laurentio existente, tenente Limiam domno Fernando Iohannis cum domno Pelagio Arie. Nos supradicti milites in hac carta quam feri iussimus manus nostras roboramu(+++)s.

Qui presentes fuerunt: domnus Iohannes Fernandi de Decia.- Domnus Fernandus Menendi de Ambia.- Domnus Alfonsus Suerii de Fornelos.- Domnus Petrus Garsie de Fornelos.Rodericus Passaro de Rovoredo.- Petrus Nariz de Fornelos.- Nuno Fernandi de Belmonti: milites testes.

Velascus Menendi miles.- Petrus Azar miles.- Rodericus Martini de Aliariz.

Velascus Nuni de Aliariz.- Petrus Arie maiordomus.- Iohannes Arie frater eius. Fernandus Portella: testes.

Fernandus Calvus prior de Melon.- Iohannes Iohannis cellararius.- Iohannes Campisinus monachus.- Frater Velascus vestiarius.- Iohannes Petri de Burgo Avie.- Martinus Iohannis monachus.- Petrus Roderici monachus: testes.

Nos etiam predicti milites Egidius Petri et Iohannes Petri quitamus vobis et monasterio supradicto sub pena in carta superius apposita illos duos forarios quos predictus pater noster vobis mandaverat, ut decetero nunquam monasterium vestrum inquietemus super illis set libere eos possideat cum iam dicta quinta super qua inter nos et vos controversia movebatur.

(+) Gregorius iuratus concilii auriensis qui scripsit testis. 
AS PARROQUIAS DO PORRIÑO, CANS E ATIOS NA DOCUMENTACIÓN DO

1233, xaneiro, 9.- Melón.

O abade Gómez de Melón afora a Xoán Arias e á súa muller Lupe Pérez a herdade de Pereiras que aquel traballaba xunto ó seu irmán Pedro Arias.

MADRID, $A H N, 1441 / 9 .-$ Carta partida por a.b.d., perg. orixinal, 120x285 mm. Latín, gótica documental. MADRID, $A H N$, Fondo monástico, Melón, Tumbo n- ${ }^{\circ} 325-\mathrm{B}$, fol. 394 r. e v., copia simple.

A...B...D. In nomine Domini nostri Ihesu Christi. Notum sit omnibus hominibus tam presentibus quam futuris quod ego Gomecius abbas de Melone una cum priore et conventu eiusdem loci damus tibi Iohannes Arie et uxori tue Lupe Petri quamdam hereditatem in termino de Pereiras que habes lucratam cum fratre tuo Petro Arie, scilicet, medietatem ex ea sicut dividis cum eo. Item damus tibi eam tali modo quod habeas illam et possideas illam iure ehereditario ( $\mathrm{sic}$ ) in perpetuum possidendam et omnis posteritas vestra et detis nobis inde vel intercessoris (sic) nostris anuatim terciam partem panis et vinis in aira et in lacare (sic) et de legumina et de lino per nostrum hominem. Et pro foris duos solidos et duos capones a festo Sancti Michaelis usque ad Sancti Martini et debetis ibi edificare domos et habitare in eis et etiam debetis esse nostros vasallos, et nos debemus defendere vos et amparare quantum meliorem potuerimus; et si forte volueritis eam hereditatem vendere vel obligare; vendatis eam nobis iusto precio, sin autem non vendatis eam militi nec sedi nec ordini set vendatis eam tali homini quod det nobis nostrum forum in pace, et quando videritis abbadem faciatis ei servicium sicut Domino.

Et si aliquis contra nostram donacionem venerit vel venerimus, iram Dei incurrat et pariet illam hereditatem duplatam aut quantum fuerit melioratam et regie voci $\mathrm{C}$ aureos persolvat.

Factum placitum in Melone era $\mathrm{M}^{\mathrm{a}}$.CC $\mathrm{CC}^{\mathrm{a}} \cdot \mathrm{LXX}^{\mathrm{a}} . \mathrm{I}, \mathrm{V}^{\mathrm{o}}$ idus ianuarii.

Qui presentes fuerunt ndonus (sic) Gomecius abbas testis, Fernandus Calvus prior testis, Nonus Velascus testis, Petrus Ruderici testis, Fernandus Burgensis testis, Petrus Nunioni subprior testis, Petrus Menendi testis, Petrus Telas testis, Petrus Petri testis, Munio Petri testis, Munio Fernandi testis, domnus Dominicus testis, Pelagius qui notuit testis.

In illo tempore in capitulo Melonis omni conventu presenti.

Recnante rex in Castella et in Legione Fernandus, episcopus in Auria Laurentio; tenente Limia Fernandus Iohannis et Pelagius Arie, maiorino regio Sanchio Pelagii.

Et iterum sicut fueritis rumpendo ita date nobis nostram direituram.

1245, xuño, 23

Don Pedro abade de Melón afóralle a Fernando Alonso diferentes propiedades en Fiscaniis, Donicoes e Pereiras.

MADRID, AHN, Fondo monástico, Melón, Tumbo n. ${ }^{\circ}$ 325-B, fol. 365 r. e v., copia simple.

Era M.CC.LXXX.III et quantum X callendas iulii. Notum sit cuntis presentem scriptum inspecturis quod ego domnus Petrus abbas Melonis prior et conventus eiusdem loci facimus pactum et placitum firmissimum in centum aureos roboratum tibi Fernando Alfonsi et omni voci tuae de illa nostra hereditate de Fiscaniis et de illa leira de Donicoys ${ }^{16}$ et illa de Peraria quam tibi Martino entergamus et devessam dabimus tibi in illo termino ad opus vineae erigendae et ligna ad opus ignis habeas ita ut grangia non gravet. Hanc hereditatem dabimus 
tibi tali pacto quod des nobis terciam partem de omni quem ibi fructa habere potueris et omnis vox tua post te per nostrum hominem annuatim et fidelissimus vasalus insuper sis et omnis vox tua posteritate?. Et ad obitum uniuscuiusque tenentis (sic) eam octaba parte de omnibus pecoribus quae ibi inventa fuerint sit nostrum in pace foro loytoosa sicut vicini tui faciunt, facias. Numquam ibi filii militum nutriant. Non eam vendas nec subpignores quoto (sic) precio nec pro tua anima des alicui, nisi nobis; quod si nos eam noluerimus iusto pretio comparare vel in pignus recipere, tali agricolae vendas subpignores qui hoc forum nobis in pace compleat annuatim; et qui supradicta non adimpleverit in pace nobis non eam habeat iure hereditario posidendam.

Si quis hoc pactum fregerit D.LX ${ }^{\mathrm{L}}$ super mille pectet penam hanc hereditatem tali tibi labores et plantes ut non defecerit per laborem.

Qui presentes fuerunt: Martinus prior testis, Fernandus suprior testis, Nunnus Petri monachus testis, frater Ariae monachus testis, frater Pelagius monachus testis, et omnis conventus.

Didacus Didaci qui notavit.

De omnibus aliis foris compleatis nobis per omnia sicut continetur in placito nostrorum hominum de Canalis.

\section{2}

1246, setembro, 1

Don Pedro Albo de Santa Marta dóalle á súa morte ó mosteiro de Melón a metade de canto ten na igrexa de San Miguel de Pereiras, unha arca e un leitón que foi de Nuno Martínez, a súa herdade de Candaosa, todo o gando que ten en Cans e unha corte.

MADRID, $A H N, 1444 / 17$.- Perg. orixinal, 145x 125 mm. Latín, gótica ducumental.

MADRID, AHN, Fondo monástico, Melón, Tumbo n. ${ }^{\circ}$ 325-B, fol. 392 r. e v., copia simple.

Era $M^{a}$.CC ${ }^{a} \cdot{ }^{2 X X X}{ }^{a} . I I I I^{a}$, kalendas setembris. Notum sit universis presentem paginam inspecturis quod ego domnus Petrus Alvus de Sancta Marta facio mandacionem meam quam nunquam possit esse contradictam. In primis mando et do et concedo ad monasterium Sancte Marie Melonis medietatem de quanto ego habuero in ecclesia Sancti Michaelis de Pireiras ad obitum meum, videlicet de habere de pane de ganado de vino de voontades et denariis de universis super batiis? de quanto mihi pertinuerit, de toto do et concedo medietatem supradicto monasterio ob remedium anime mee. Insuper mando ibi unam arcam et unum lectum qui fuit de Nuno Martini et mandavit illa ad monasterium. Et mando ibi totam meam hereditatem de Candaosa quam ibi habeo de comparadea et de gaanadea, et? mando ad monasterium totum meum ganadum quod habeo in Canes, preter unum armentium qui habeant mei filii et nunquam levent illum de Canes, set habeant inde almalium vel vacam vetulam sicut et ego.

Qui presentes fuerunt: Petrus abbas, Iohannes Petri monachus, Petrus Petri, Rodericus Petri, domnus Froya, Petrus Cultello, Petrus Didaci, Nuno Petri Curvo, Nunus Petri clericus de Nugeira.

${ }^{16}$ Donicoys: transcribímolo deste xeito aínda que no documento di de Nicoys. Esta segunda forma debe interpretarse como unha mala lectura de Donicoys. 
AS PARROQUIAS DO PORRIÑO, CANS E ATIOS NA DOCUMENTACIÓN DO

1250, marzo

Pedro abade de Melón afóralle a Xoán Iohannis e á súa muller María Pérez, e a Afonso Iohannis e á súa muller María Nunez a herdade de Enfesta.

OURENSE, ACO, Fondo pergameos, Melón, n. ${ }^{\circ}$ 651.- Perg. orixinal, 133×150 mm. Latín, gótica documental.

MADRID, $A H N$, Fondo monástico, Melón, Tumbo n. ${ }^{\text {o } 325-B, ~ f o l . ~} 372$ r., copia simple.

Catálogo: LEIRÓS, Catálogo, nº 651.

Edita: SOTO LAMAS, M.J., Colección, nº 129.

Era $\mathrm{M}^{\mathrm{a}}$.CC ${ }^{\mathrm{a}}$.LXXX ${ }^{\mathrm{a}} \mathrm{VIII}{ }^{\mathrm{a}}$, mense martii. Noscant presentes et futuri quod nos Petrus abbas, prior et conventus de Melon damus tibi Iohanni Iohannis et uxori tue Marie Petri et tibi Alfonso Iohannis uxorique tue Marine Nuniz et omni voci vestre ipsam nostram hereditatem de Enfensta (sic) per caminum vetus de Enfesta, et de omni parte sicut ego Petrus abbas eam vobis divisi; hanc hereditatem damus vobis tali pacto quod laboretis eam ut non defficiat per laborem et usque ad tres annos sit culta et plantata, et detis inde nobis annuatim terciam partem de omni fructu per nostrum hominem in pace. Nullus eam habeat pro hereditate nisi qui hoc forum supradictum nobis in pace persolverit annuatim et noster vasallus fuerit fidelis; sicut nos eam modo habemus et possedimus, ita vos eam habeatis et possideatis.

Qui hoc pactum fregerit, $\mathrm{C}^{\mathrm{m}}$ aureos alteri parti pectet; placito nichilominus suo robore roborato.

Qui presentes fuerunt: Martinus prior, Fernandus subprior, Rodericus Petri, Rodericus Martini, Fernandus vestiarius, Fernandus Calvus, Gundisalvus cantor, Dominicus Didaci, frater Pelagius de Canis. De secularibus: Fernandus Alfonsi de Donicoes, Pelagius Iohannis de Campos, Nunus Iohannis de Novigilde.

Iohannes qui notuit et est testis.

1252, novembro

Pedro Moogo, Maior Méndez, Elvira Nunez, Pedro Nunez, Pedro Méndez, Xoán Méndez, María

Méndez e Maior Méndez venden a herdade de Campos por nove soldos.

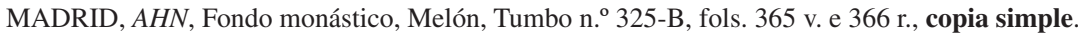

In Dei nomine, amen. In posterum noticiam veniat et presentium quod nos Petrus Moogo, unam sextam, et ego Mayor Menendi, medietatem, et ego Elvira Nuniz et Petrus Nuniz, medietatem unius sexte, et ego Petrus Menendi et Iohannes Menendi et Maria Menendi et Maior Menendi, aliam sextam, vendimus et concedimus iure hereditario in perpetuum possidendam ipsam nostram hereditatem de Campis quantam ibi habemus sicut supra diximus cum ingressibus et egressibus montibus et pascuis, fontibus, cultis et incultis et cum omnibus ad vocem vestram pertinentiis in eadem, pro precio quod nobis et vobis complacuit, videlicet, unicumque nostrum novem novem (sic) solidos, quos a bobis (sic) in presenti penes nos recepimus.

Si quis igitur huic vendicioni nostrae [...]que emptioni tam ex parte nostra quam extranea in aliquo contra ire voluerit, iram Dei omnipotentis et nostram habeat sempiternam et de 
predictis perditionis sententiam recipiat in eternum et voci regie centum marabitinos pectet ipsa hereditate vobis in duplum aut quadruplum nichilominus restaurata.

Facta carta venditionis sub era M.CC.LX ${ }^{\mathrm{L}}$, mense novembri, regnante Legione et Castella Domino Afonso, tenente terram domno Ferdinando Iohannis, episcopo in Tuda domino Egidio Petri.

Presentibus et audientibus Petrus Moogo Rabicio, Martino Laurencio de Doniquees, Petrus Petri dicto Allote de Sangueneda.

Iohannes qui notavit (+).

1252

O abade Pedro de Melón afóralle a Martín Domínguez, a Xoán Iohannis e a Pedro Iohannis, coas súas respectivas esposas, a herdade de Fontelo.

OURENSE, ACO, Fondo pergameos, Melón, n. ${ }^{\circ}$ 681.- Traslado realizado por Johannes Peres notario jurado en terra de Lourinna en logar de Bernal Eans notario del rey en Toronno, non indica a data do traslado. Perg., 165x290 mm. Latín, gótica documental.

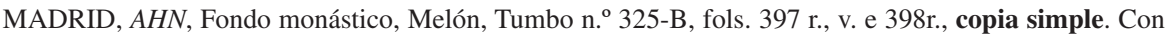
data equivocada de 1202 .

Catálogo: LEIRÓS, Catálogo, $\mathrm{n}^{\circ} 681$.

Edita: SOTO LAMAS, M.J., Colección, nº 135.

Era $M^{a}$.CC ${ }^{a}$.LXXXX ${ }^{a}$. Notum sit omnibus tam presentibus quam futuris quod nos Petrus abbas et conventus de Melone facimus pactum et placitum firmum in L aureos roboratum tibi Martino Dominici et uxori tue Marie Iohannis, et tibi Iohanni Iohannis et mulieri tue Guncine Martini et tibi Petro Iohannis et uxori tue Maiori Petri omnique voci vestre de ipsa nostra hereditate de Fonteelo pelo marco do souto da Bouça Camposa como se vay pela pedra desinada da costa et se vai aa pedra do bico do agro de Domingos et como se vem porlo porto da Escaarada et inde como se vay pelo regeyro de Fonteelo a supe como intra in rivuolo, excepto fundadoria aliena. Damus, inquan, vobis predicta tali pacto quod bene laboretis eam et plantetis ita quod non deficiat per laborem; et omni frutu que ibi habueritis detis nobis terciam partem per nostrum hominem annuatim, excepto olera et porrum; et porcionem nostram ducatis ad cellarium nostrum de Canes; et foros quos ipsi homines de ipsa villa faciunt monasterio, vos per omnia faciatis. In obitu vero cuiuscumque vestrum virorum, scilicet, et mulierum, octavam partem ganati tocius; et sitis nostri vasalli fidelisimi et non metatis ibi filios nec filias militum nec aliorum potencium, non vendatis eam cuilibet nisi nobis; non subpinoretis, quod si nos iusto precio eam noluerimus emere vel in pinore accipere, tali agricole vendatis qui nobis forum supradictum supleat annuatim; nullus eam vocitet pro sua, nisi qui in ea habitaverit et hoc forum annuatim nobis adimpleatum.

Qui hoc pactum fregerit dictam superius alteri parti pectet penam. Nichilominus placito in suo robore permanente.

Regnante Domino Fernando in Legione, Castella et Tolleto, Corduba, Sibila, tenente Toronio domno Fernando Iohannis, eius maiordomo Fernandus Faval, maiorino regis Munione Fernandi, episcopo in Tuda domno Egidii.

Et que potuerimus gaanar da Bouça Camposa et do casal de Froya que souto seia, darmosvolo. 
Qui presentes fuerunt: Petrus prior, Petrus subprior, Fernandus cellararius, Rodericus vestiarius, Petrus Cupino, Fernandus Fernandi, Iohannes Guntin, Rodericus Guntin, Petrus qui scripsit.

Et eu Johannes Peres notario jurado en terra de Lourinna en logar de Bernal Eans notario del rey en Toronno este plaso en mina presença fiz tresladar et em este treslado o sinal do dito Bernaldo Eans y puge que tal he (+).

1253

O abade de Melón frei Pedro afóralle a Pedro Moogo unha herdade no lugar de Castenaria.

MADRID, AHN, 1446/16.- Carta partida por a.b.d., perg. orixinal, 75x125 mm. Latín, gótica documental. MADRID, $A H N$, Fondo monástico, Melón, Tumbo n. ${ }^{\circ} 325-\mathrm{B}$, fol. 374 r., copia simple.

A...B...D. Era $M^{a}$.CC ${ }^{a} .{ }^{2} X X X X^{a} . I^{a}$. Notum sit cuncti presentibus et futuris quod ego frater Petrus abbas Melonis et conventus eiusdem facimus pactum et placitum firmissimum in $\mathrm{C}^{\mathrm{m}}$ solidos roboratum tibi Petro Moogo (tachado: et tota tua generatione) omnique voci tue damus tibi ipsam nostram hereditatem nominatam in loco que vocatur Castenaria, quomodo dividitur per Galifaes et deinde per caminum et dividitur cum Petro Osso et per rivulum. Tali pacto damus tibi ut des nobis inde annuatim unam talegam de tritico et tres talegas de ceveyra, unum solidum pro festum Sancti Michahelis. Ducat nobis porcionem nostram ad cellarium nostrum de Canalibus; quando venerit dictis abbas ad terram, faciat ei servitium sicuti Domino; similiter faciatis prior et cellerarium. Nullus vocitet eam pro hereditate, nisi qui in illa habitaverit; nunquam mitatis ei filios nec filias militum nec alio potemtem; sitis nostri vassalli fidelissimi, non vendatis nec imppignoretis nisi nobis (tachado: quod si no), nec pro animabus vestris detis nisi nobis; quod si nos noluerimus emere, tali agricole detis qui nostrum forum in pace faciat annuatim.

Et qui hoc pactum fregerit alteri parti pectet. Placito suo robore permanente. Ad obitum tuum des nobis quartam partem de tuo habere et omnis qui ibi habitaverint.

Qui presentes fuerunt Iohannis Nunionis, Petrus Nunionis, Salvatori Petri, domnus Munio cellarario de Toronio.

Iohannes qui notuit.

1253

Frei Pedro abade de Melón afóralle unha metade a Xoán Iohannis e a outra metade ós fillos de Mariña Martínez das castañas e dunha herdade no couto de Cans.

MADRID, $A H N$, 1446/17.- Perg. orixinal, 80x138 mm. Latín, gótica documental.

MADRID, AHN, Fondo monástico, Melón, Tumbo n. ${ }^{\circ} 325-\mathrm{B}$, fol. 365 v., copia simple.

Observación: Os dous asteriscos que hai na transcrición significan que o amanuense puxo sendas notas de chamada.

Era $M^{\mathrm{a}}$.CC ${ }^{\mathrm{a}} . \mathrm{LXXXX}^{\mathrm{a}} . \mathrm{I}^{\mathrm{a}}$. Notum sit cuncti presentibus et futuri<s $>$ quod ego frater Petrus abbas Melonis, prior et conventus eiusdem facimus pactum et placitum firmissimum in $\mathrm{C}^{\mathrm{m}}$ aureos roboratum tibi Iohanne Iohannis et filius Marine Martini per medium. Damus tibi ipsas nostras castaneas quas modo tenet et alias quas plantaveris in tali loco plantes eas ut non noceat panem et vinum insuper in ipso nostro capto (sic) de Canalibus, et des inde nobis annuatim per nostrum hominem medietatem ad cisternam et de destelas similiter et de aliam hereditatem 
de Dominicus Cresconet. Damus eam tibi per tali pacto et istam hereditatem divides eam inter te et filios Marine Martini <et> illos qui habitaverint in capto nostro de Canalibus habeant eas castaneas et hereditatem iure hereditario in perpetuum possidendam de ipsam hereditatem de Dominico. Dle/s inde nobis annuatim unum puzale de vino et medietatem de castaneas de regalengo, * et si non habuerit vinum in terra, des unum quartarium de pane.

Et qui hoc pactum fregerit alteri parti $\mathrm{C}^{\mathrm{m}}$ aureos persolvat, placito suo robore permanente * et alias de hereditates medietatem.

Qui presentes fuerunt: Petrus prior, Fernandus suprior, Martinus cellararius de Toronio, Fernandus Calviis, Rodericus Martini, Rodericus vestiarius, Petrus infirmarius, Gundisalvus cantor, Rodericus succentor.

Iohannes qui notuit.

1255, febreiro, 1

María Iohannis véndelle ó mosteiro de Melón a herdade chamada Agro de Campos que tiña de súa nai Maior Salvadorit.

OURENSE, ACO, Fondo pergameos, Melón, n. ${ }^{\circ}$ 686.- Perg. orixinal, 100x116 mm. Latín, gótica documental.

MADRID, AHN, Fondo monástico, Melón, Tumbo n. ${ }^{\circ}$ 325-B, fol. 366 r., copia simple.

Catálogo: LEIRÓS, Catálogo, nº 686, dando equivocadamente a era 1290, sendo a correcta 1293 (= ano 1255), pois estima que os tres últimos numerais da data $\left(\mathrm{III}^{\mathrm{a}}\right)$ pertencen á expresión do día do mes.

Edita: SOTO LAMAS, M.J., Colección, nº. 149.

In Dei nomine. Notum sit omnibus presentibus et futuris quod ego Maria Iohannis vendo vobis abbas et conventum de Melon ipsam meam hereditatem que vocitat Agro de Canpos, quod habeo de matre mea Maior Salvadorit, cum omnibus pertinentiis suis sicut vendiderunt illum germanos meos et pro precio quod michi et vobis bene complacuit, scilicet, II solidos et IX denarios et unum pro revura (sic). Vendo inquam monasterio de Melon ut habeat et possideat in perpetuum.

$\mathrm{Si}$ aliquis homo venerit qui hanc meam vendicionem irrumpere voluerit, Dei maledictionem habeat et quantum calumniaverit in duplum redat et domino Iterre/ C solidos pectet.

Facta venditione era $\mathrm{M}^{\mathrm{a}}$.CC ${ }^{\mathrm{a}}$. LXXXX.III ${ }^{\mathrm{a}}$, kalendas februari, regnante rege in Legione et Castella et Sibilia Domino Alfonso, tenente terra de Toronio domno Fernando Iohannis, episcopo in Tuda domno Egidio.

Qui presentes fuerunt et testes: Duran de Canalibus, Petrus Martini de Teelas, Gundisalvus Larpote de Salvaterra, Iohannes Nuniz de Caes, Martinus Martini de Viso, Martinus Batel.

(+) Iohannes qui scripsit. 
AS PARROQUIAS DO PORRIÑO, CANS E ATIOS NA DOCUMENTACIÓN DO

1255, maio*, 2

Mariña González e a súa irmá María González venden a frei Munio, celareiro do mosteiro de Melón, unha parte do monte chamado Castro de Fonteelo, por doce soldos.

MADRID, AHN, 1447/20.- Perg. orixinal, 145x126 mm. Latín, gótica documental.

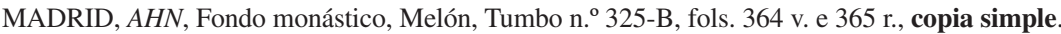

Observación: Maio*: Tómase do Tumbo n. ${ }^{\circ} 325-B$ do AHN.

In Dei nomine, amen. Notum sit omnibus presentibus et futuris quod ego Marina Gonsalvit et germana mea Maria Gonsalvit vendimus vobis frater Monio celarario Melonis ad quarta da tercia de ipso monte quod vocitant Castro de Fonteelo pro precio nominato XII solidos tantum nobis et vobis placuit, et de precio non remansit pro dare.

$\mathrm{Si}$ aliquis homo venerit ex parte nostra vel extranea ad irrumpendum factum nostrum sit maledictus ad Domino et quantum calumpniaverit tamtum dupplet et insuper domino terre $\mathrm{XX}^{\mathrm{ti}}$.IIII ${ }^{\text {or }}$ solidos persolvat, et carta in suo robore permanente.

Facta carta sub era $\mathrm{M}^{\mathrm{a}}$. $\mathrm{CC}^{\mathrm{a}}$. $\mathrm{LX}^{\mathrm{La}} \cdot \mathrm{III}^{\mathrm{a}}, \mathrm{VI}^{\mathrm{o}}$ nonas [maii*], regnante rege Domino Alfonsus in Legione et in Castella et in Sibillia, [episcopo in Tuda] domno Egidio, tenente terra domno Fernando Iohannis, maiordomo in Laurina Petro do Baal.

Qui presentes fuerunt: Petro Porrino testis, Fernan Nuniz testis, Fernan Porrino, Martin Nuniz, suo cunote Iohanne d'Alfaya, Petro Alvo, Petro Seco.

Ego Iohannes Iohanni notarius in terra de Lourina qui notuit per mandatum domni Roderici Suariz meirino mayori in Gallecia.

1256, xaneiro

Pedro Pérez, fillo de María de Deus de Barrio, véndelle ó abade de Melón don Pedro unha parte da herdade de Donicoes, por dez soldos e oito diñeiros de moeda leonesa.

MADRID, $A H N$, 1448/7.- Perg. orixinal, 232x57 mm. Latín, gótica documental.

MADRID, $A H N$, Fondo monástico, Melón, Tumbo n. ${ }^{\circ}$ 325-B, fol. 397 r., copia simple.

In Dei nomine, amen. Notum sit omnibus presentibus et futuris quod ego Petrus Petri filii de Marie de Dei de Barrio et voci mee vendo vobis abbas domno Petro de Melon et conventu eiusdem loci terciam de una sesta de ipsa hereditate de Donicones quam habui de matre mea Marie de Dei, scilicet, pro precio nominato X solidos et VIII denarios monete Legione de quod iam suum pagati; et debeo anparare vobis cum istan venditionem per me et per omnia mea bona habita et abenda.

Si quis homino venerit qui hoc factum meum conrumpere voluerit, in dupplo componat vobis istam venditionem et insuper domino terre $\mathrm{XX}^{\mathrm{ti}}$.I solidos et IIII denarios persolvat, et carta in suo robore permaneat.

Facta carta sub era $\mathrm{M}^{\mathrm{a}}: \mathrm{CC}^{\mathrm{a}} \cdot \mathrm{LX}^{\mathrm{La}}$.IIII ${ }^{\mathrm{a}}$ in mense ienuarii, regnante rege Domino Alfonso in Legione et in Castella, episcopo in Tuda domno $<$ E $>$ gidio, tenente terra domno Fernando Iohannis, de manu eius Fernandus Faval, maiordomo Petro do Baal.

Qui presentes fuerunt: Fernando Petri dicto Porrino.- Petro Chouteiro.- Martino dicto Corvo.- Fernando dicto Corvo.- Iohannes Balero de Caaes, testes.

Ego Iohannes notarius in terra de Lourina qui notuit. 
1256

Pedro Nunez dito Cornudo véndelle ó abade de Melón don Pedro media sexta das Cortinas da herdade de Barro e cavada de Fontelo, por vinte soldos e nove diñeiros.

MADRID, $A H N$, 1448/11.- Perg. orixinal, 95x175 mm. Latín, gótica documental.

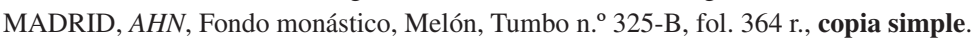

In Dei nomine, amen. Notum sit omnibus presentibus et futuris quod ego Petrus Nuni dicto Cornuto et voci mee vendo vobis abbate domno Petro de Melon et conventu eiusdem loci ipsam mediam sextam das cortinas de hereditate de Barro et cavada de Fonteelo, videlicet, pro $\mathrm{XX}^{\mathrm{ti}}$ solidos et VIIII denarios de quo iam suи (sic) pagati et debeo senper amparare istam venditionem per me et per omnia mea bona habita et abenda. Ego Petrus Nuni renuncio ex tunc anbas hereditates quas vendidi ad possidendum monesterii in perpetuum, et si frater meus venerit ad inquirendum portionem suam quam emi ad fratrem meum, ego Petrus Nuni dicto Cornuti per meam bonam abitam et abendam intus cauto et foris ad defendendum nos cum ipsas quas sunt nominatas.

Si quis homo venerit qui hoc factum meum conrumpere voluerit in dupplo componat vobis istam herediatem et insuper domino terre $\mathrm{X}^{\mathrm{La}}$.I solidos et medium persolvat et carta in suo robore permaneat.

Facta carta sub era $\mathrm{M}^{\mathrm{a}}$.CC ${ }^{\mathrm{a}}$. $\mathrm{LX}^{\mathrm{L} a}$.IIII ${ }^{\mathrm{a}}$, regnante rege in Legione et in Castella Domino Alfonso, episcopo in Tuda domno Egidio, tenente terra domno Fernando Iohannis, de manu eius Fernando Faval.

Qui presentes fuerunt: Pelagius Iohannis de Donicones.- Nuno Iohannis de Donicones.Iohanne Fanon.- Iohanne Martini dicto Terciado de Salzeda: testes.

Ego Iohannis Iohanni notarius in terra de Lourina qui notuit.

1260, abril

Fernando Pérez e Xoán Pérez véndenlle ó mosteiro de Melón as súas propiedades en Cans e en Donicoes, por cento dez soldos.

MADRID, $A H N$, Fondo monástico, Melón, Tumbo n. ${ }^{\circ}$ 325-B, fol. 364 r., copia simple.

In Dei nomine, amen. Ego Ferdinandus Petri et ego Iohannes Petri et omnis vox nostra vobis fratri Nuno celerarius de Melon in voce fratris Ferdinandi abbatis Melonis et conventus eiusdem loci facimus vobis cartam de Canenes ${ }^{17}$ et de Donicones quantum nos ibi habemus de parte de nostra matre ad montes et ad fontes damus vobis et concedimusea in secula seculorum pro pretio quod hi accepimus scilicet $\mathrm{C}$.X solidos et $\mathrm{a}<\mathrm{m}>$ plius nihil remansit pro dare.

Et si quis evenerit qui hanc cartam irumpere voluerit, quantum callumniaverit tantum duplet domino terrae, peitet X.VIII solidos et carta sit firma.

Fauta ista carta sub era M.CC.LX ${ }^{\mathrm{L}}$.VIII, mense aprilis.

Qui presentes fuerunt: Ferdinandus Petri dicto Porrino, Nunnus Iohannis de Canes, Pelagius Iohannis de Campos, Martinus Nuniz de Porrino, Gaciae Fanon testes.

Et ego Petrus Martinz notarius Laurinae de mandato Martini Iohannis notarii.

${ }^{17}$ Posiblemente trátase dunha mala lectura de Canes. 
1264, xuño, 10

Xoán García milite de Lira e a súa muller María Suárez véndenlle a Xoán abade de Melón parte da herdade de Barro que fora de Pedro Calvo de Villis, por trinta soldos.

MADRID, $A H N, 1450 / 16$.- Perg. orixinal, 172x122 mm. Latín, gótica documental.

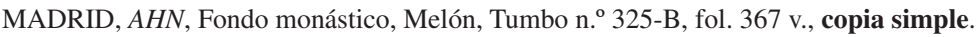

Notum sit omnibus quod ego Iohannis Garsie milles de Lira pro me et pro uxore mea Maria Suarii, Nunus ausenti, et pro tota voce nostra vendo firmiter ac concedo in perpetuum vobis Iohanni abbati et conventui Melonis omnique voci vestre quartam partem de duabus quintis de sesta hereditatis de Barrio que fuit de Petro Calvo de Villis quam habebat ex parte avi Petri de Barrio, et habet iacencia ipsa dicta hereditate in Donicoes et in couto de Caes sicut dividit per Rivolum Malum, ad montem et ad fontem, con (sic) omnibus suis pertinentiis ubi eam potueritis invenire pro nominato precio $\mathrm{XXX}^{\text {ta }}$ solidos et de rebora unum arietem apreciato in II solidos; et de toto fecistis michi pagam, ex hac die habeatis et posideatis iure et in perpetuum.

Et si aliquis de nostra aut de extranea contra hanc venditionem venire voluerit, iram Dei habeat et nostram maledictionem et duplum calumpnie nobis pectet et regie parti LXX ${ }^{\text {ta }}$ solidos, carta ista maneat in suo robore.

Facta carta in era $\mathrm{M}^{\mathrm{a}}$.CCC ${ }^{\mathrm{a}}$ secunda, IIII idus iunii, regnante rege Domino Alfonso in Legione, episcopo in Tuda domno Egidio, tenente Toronio domno Fernando Iohannis.

Ego supradictus Iohannis Garsie teneor amparare vos et vocem vestram dictam venditionem per omnia bona mea mobilia et inmobilia que vobis in presenti manu mito in omni tempore.

Qui presentes fuerunt: Fernandus Petri de Porrino, Tomas Fanion, Iohannis Fanion, Gondisalvus Fernandi, frater Fernando et alii plures: testes.

Ego Rodericus Martini subnotarius iuratus de Martini Iohannis (+) plubico [nota]rio in terra de Laurina ad hoc adibitus et rogatus interfui et propia manu [scripsi] et signum posi et confirmo.

1274

María Martínez, filla de Miguel Eans, e o seu marido Martín Paz dito Rata véndenlle ó mosteiro de Melón a metade do agro da Cima, que foi de Bernardo Martínez.

MADRID, $A H N$, Fondo monástico, Melón, Tumbo n. ${ }^{\circ}$ 325-B, fols. 366 v. e 367 r., copia simple.

[...] nome do abade [...] nos compramos [...] nos teemos partida et marcada da [...] compramos de Pedro Eans de Campos et a outra nosa leyra que foy [...] como parte dende Juan Batalla et vay ferir na de Pedro Corvo et [...] por precio nomeado de $\mathrm{L}$ soldos en diñeiros alfonsis et hun [...] en cada et dar et hun cal [...] et de todos nos [...] a estas heredades sobreditas por nos $[\ldots]$ in secula seculorum.

Et se algun [...] ven para usarla o para y cooniar a tanto [...] et esta carta sempre sea firme et estabil en sua rebor.

Feita a carta seis [...] era M.CCC.XII anos, reinando Domino Alfonso en Leon et en Castilla, tenente Toronio don Juan Fernandez [...]. Ts que presentes foron Martin Paaz, IDiego/ 
dicto Nouso, Fernan Paz, Juan [...] de Campos, Pedro Miguelez de Valladares, et eu Pedro Lourenzo tenente as veces [...] notario del rey en terra de Antenza et de Laurina en esta carta escrivi por mina propia mao et foy presente $<$ et $>$ feci por seu mandado porque el non era nen esta, este meu nome et seu signal que tal est (+).

In Dei nomine, amen. Sabean quantos esta carta viren que eu Maria Martinz filla que fuy de Miguel Eans por rogo et ensembra de meu marido Martin Paz dito Rata por nos et por toda nossa voz a vos frey Domingo celareiro de Caes vendemos a vos e ao moesteiro de Santa María de Melon o meyo de aquel agro que chaman da Cima o qual foi de Bernardo Martinz [...] que jas so o chouso de Pedro Mendez de Ardegunda ${ }^{18}$ en no couto de Caes. Damos et outorgamos o meyo do do (sic) sobredito agro por precio nominado LXXX floren ? $^{19}$ de diñeiros blancos de que nos outorgamos por ben pagados et prometemos vos a emparar con dita heredade por nos et por todas nosas voces de as quales como dito he [...] in secula seculorum.

Et se algun de nos quisier in contra esta carta $[\ldots]$ o tanto a vos $[\ldots]$ pena $[\ldots]$ et esta carta seia firme et valedeira en sua rebor.

Feita a carta era M.CCC.XII anos, regnante Domino Alfonso in Legione et in Castella [...] don Alfonso Fernandez [...] Nuno Martinez, et ego Juan Paz [...] dito do Real, Fernando Nunez do Rial de Caes. Et eu Gonzalvo Lopes, tenente as veces de Pedro Calzado notario publico en terra d'Antenza et de Laurina, a todas estas cousas presente fuy, et a rogo das partes esta carta figi et pugi seu signal que tal he (+).

Ó pé o amanuense engade a explicación que segue: "Este pergamino esta mui dificultoso por lebantada la letra y raspado por arriba y bastante oscuro, pero lo principal de el quasi esta sacado".

1286, abril, 26

Paio Johannes dóalle ó mosteiro de Melón as súas propiedades en Cans.

MADRID, AHN, Fondo monástico, Melón, Tumbo n. ${ }^{\circ}$ 325-B, fol. 366 r., copia simple.

In Dei nomine, amen. Sabeam quantos esta carta viren et ouviren como eu Paay Johannes con toda nuestra voz dou et outorgo para sempre a Santa Maria de Melon quanta heredade et chantado eu ey en Caes con quanto y ey movil et reyz, por tal preito que o abade ou aquel que estever en seu lugar proveades a min de comer et de beber et de vestir asi como a cada hun dos mancebos dessa graña de Caes.

Et se alguen de miña parte ou da outra contra esta miña doacion quiser passar, peite a vos esta heredad et este a vos dobrado et ao rey da terra por pea $\mathrm{C}$ maravedis, et a doacion vala para sempre.

Feita a doacion era M.CCC.XX.IIII anos, quatro dias por andar do mes de abril.

Que foron presentes: Fernando Varcia, Juan Paaz et Nuno Fernandi dito Pato moradores das provanzas de Donicoes, Juan Nuniz do Real de Caes, Juan Ferreiro, Pasqual Eans seu fillo, et outros.

Et eu Fernando Martinz notario jurado en terra de Lourina a todas estas cousas presente fui y, et por miña mao esta carta escribi et meu signal y pugy que est tal (+).

\footnotetext{
${ }^{18}$ Podería tratarse dunha mala lectura de Liñar de Gunda.

${ }^{19}$ Posible mala lectura do amanuense
} 
1287, xuño, 15

Xoán Suárez véndelle ó abade de Melón don Pedro as súas herdades en Liñar de Gunda, por trescentos soldos.

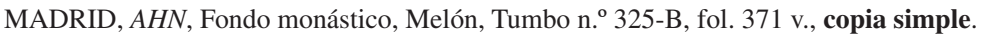

In Dei nomine, amen. Sabean todos quantos esta carta viren et ouviren que eu Juan Soarez cabaleiro de Ateos con toda miña voz vendo firme et outorgo para sempre a vos don Pedro abade de Melon et oo convento desse lugar et a toda vossa voz quanto heredamento eu ey en Linar de Gundi et possuo et en jur et en mao teño ad montem et ad fontem con todas suas perteencias por precio que de vos recibi et de que been soo pagado CCC soldos desta moneda que ahora corre $<$ de $>$ II diñeiros por $c a<$ da $>$ soldo, a posse et a jur do dito heredamento de min tollo, et en vosso jur et en vosa mao meto, que aiades et possuyades in secula seculorum.

Et se alguen de miña parte contra esta venda quiser pasar peite a outra parte a herdade dobrada et ao señor da terra por pena peite DC soldos et a venda valla para sempre.

Et eu Juan Soarez sobredito devo $a a_{u} n^{20}$ a renda de esse heredamento en miña vida tanto et depoys ser libre de todo embargo.

Era M.CCC.XX.V anos, quinze dias de juño.

Que foron presentes: Martin Nuniz de Porrino, Nuno Pato, Pedro Martinz de Porrino, Juan Pelaez e Fernando Garcia de Ateos, ts. Et eu Pedro Martinz notario jurado en terra de Laurina presente fui et por mia mao esta carta escribi et meu signal y pugy que est tal (+).

1288, xuño, 24

O abade de Melón don frei Estevo afóralle a Xoán Lourenzo, á súa muller Mariña Eans, ós seus fillos e ós seus netos o casal de Fontelo.

MADRID, AHN, Fondo monástico, Melón, Tumbo n. ${ }^{\circ}$ 325-B, fols. 360 v. e 361 r., copia simple.

Sabean quantos esta carta viren como nos don frey Estevo abad do moesteyro de Santa Maria de Melon e o convento do dito lugar damos et outorgamos a foro a vos Juan Lourenzo et a vossa muller Marina Eans et a vosso fillo et a vosso neto ou netos, o noso casal de Fontenlo que tragia a jur et a mao Juan Lourenzo et Urraca Fernandez sua muller et como parte dos outros lugares de Fonteelo do esta y aforado por todo o que pudo e uso que tiña Gonzalvo Eans de Fonteelo salvo as castañas se han hi que has aia o dito Juan Lourenzo ou aquelles que pertenescan ao dito [...] et con dito? quanto labredes et moredes et pobredes et guaredes? ben como non perca por mingoa de lavor nin outro paramento nen de outros boos paramentos. Et dedes a nos et ao dito moesteyro cada ano tercia de pan et de viño et de lino et de legumia et de castañas et de froyta et quanto Deus y der le ao moordomo que por nos estiber na/ graña de Caes ao qual podades dar de comer et de beber comunalmente nec recebir o nosso quiñon todas las novidades, et traigades en cada hun ano das ditas novidades por vosa custa en paz et en salvo aa dita graña de Cans et que [...] estedes en o couto de nosso moordomo et quen non

${ }^{20}$ Posible mala lectura do amanuense. 
morar o dito casal non no dian por herdade et vos et as ditas vozes depus vos. Et fagades sempre ao abade do dito moesteyro quando for y en Caas huna vez en lo ano como a señor. Et paguedes de foro cada ano assi como paguen dos outros casares de Caas et a loytosa del foro. Et seredes nossos vasallos servientes et obedientes et non as entreguedes a outro señorio apostolico et non dedes hi fillo et dona nen de cavaleiro nen de escudeiro nen fidalgo, et non posades vender o dito casal nen partir del nen dar nen doar nen por vossas almas dar, sino ao dito moesteiro et a saimento de cada una das voces quedaran ao dito monasterio acotagado (sic) todo o gando que huber et [...] et outrosi con la oitava do gando que y houver et dar por elo et recebelo sen embargo nenhun. Et eu dito Juan Lourenzo por min et por la dita miña muller que presente non he et pus as voces pus nos, assy recebo de vos ditos abade et convento o aforamento por las ditas condiçoons, et nos dito abades abade et convento assi lo outorgamos.

Et qualesquier das partes que contra esto foren, peite a outra parte por pena $\mathrm{C}$ maravedis et a voz del rey outros tantos, et a carta et aforamento fique firme no tempo sobredito.

Et que esto seia certo mandamos ende faser duas cartas partidas por divisio de a.b.c. en que ponemos nosos sellos.

Et nos don abade sobredito de Santa Maria de Melon, XXIIII dias de juño era de M.CCC.XX.VI anos.

Ts frey Juan Martinz prior, Martin Fernandez por [...] frey Lorenzo de [...] et outros.

Et eu Martin Gomez os ditos plaços escrivi.- Martin Gometii [...].

Ó pé o amanuense engade a explicación que segue: "Este es un pergamino que tiene saltada la letra y mal se puede entender ni leer".

1289, xullo, 29.- Ourense.

Contenda entre don frei Pedro, abade de Melón, e Xoán Pérez dito Barreiro, crego de Santa Marta de Ligurin, pola metade de dous casais en Liñar de Gunda, que se resolve a favor do primeiro.

MADRID, $A H N, 1454 / 15$.- Perg. orixinal, 170x320 mm. Latín, gótica documental.

MADRID, AHN, Fondo monástico, Melón, Tumbo n. ${ }^{\circ} 325-\mathrm{B}$, fol. 356 r. e v., copia simple.

Noverint universi quod cum coram me Roderico Roderici archidiacono de Baronçelli in ecclesia auriensi, inter partes infraescritas a Sumo Pontiffice, iudice delegato. Domnus frater Petrus abbas monasteri de Melon tudensis diocesis pro se et conventu eiusdem monasterii convenirunt in iudicium Iohannem Petri dictum Barreyro clericum de Sancta Martha de [Ligurin] petens quod dictus Iohannis Petri expediret dicto monasterio medietatem duorum casalium cum omnibus iuribus directuris et pertinentiis suis que [ca?]salia sunt in filigresia Sancte Eolalie de Ateos in cauto de Canales in loco qui dicitur Lignar de Gundia, in quorum uno casalium moratur ad presens Iohannes Fernandi dictus de Montaos et in allio moratur Rodericus Roderici. Et tunc dictus clericus respondit quod non credebat dictum heredamentum dictum monasterii spectare ut in dicta petitione continebatur; et tunc predictus abbas dixit per domnum fratrem [...] quondam abbatem dicti monasterii et per conventum eiusdem afforatum fuisse Petro Albo et filio suo Petro Petri ante[ce]ssori iamdicti Iohannis Petri dicti Barreyros secundum continebatur in quodam publico instrumento diviso per alfabetum inter eos, quod instrumentum predictus abbas in iudicio demostravit; contra quod, dictus Iohannis Petri clericus de Sancta Marta nullam [...] rationem excusationem seu deffenssionem sive ius aliquod pro se allegavit nisi quod fuerat 
in possessione dicti herdamenti a tempore mortis dicti Petri Albi quondam antecessoris sui; quod Iohanne Petri a me dicto archidiacono interrogato? si pro se aliud ius sive rationem vel deffenssionem in dicto herdamento habebat quod doceret et [...], respondit se [a]liud ius non habere nec possessionem predictam. Ego vero predictus archediaconus iudex delegatus pro rescripto apostolico et instrumento afforamenti a parte dicti abbatis oblato, auditis rationibus hinc inde propositas pro tribunali sedens, deliberatione prehabita sentenciando pronuncio herdamentum in petitione dicti abbatis contentum et secundum quod in instrumento afforamenti plenius continetur ad dictum monasterium de Mellone penitus pertinere, mandans sententialiter predicto Iohanni Petri dicto Barreyro quod ex nunc eidem monasterio expediat herdamentum predictum cum omnibus iuribus, directuris et pertinentiis ad ipsum herdamentum pertinentibus, et similiter quod ex nunc superdicto herdamento contra dictum monasterium aliquatenus moveat questionem. In cuius rei testimonium ego predictus archidiaconus presentem sententiam sigilli mei feci munumine roborari.

Actum Aurie IIII ${ }^{\circ}$ kalendas augusti, era $\mathrm{M}^{\mathrm{a}} \cdot \mathrm{CCC}^{\mathrm{a}} \cdot \mathrm{XX}^{\mathrm{a}}$ septima.

Presentibus ad hoc vocatis: Martino Iohannis perticario auriense, Laurentio Ordonii et Roderico Iohannis clericus chori auriense, Garsia Petri rectore ecclesie de Gudes archidiaccatus Limie, et Gunsalvo Iohannis capellano ecclesie Sancti Iacobi de R[ib]arteme, et Iohanne serviente supradicti Martini Iohannis portarii.

Et me Iohanne Martini publico auriense notario qui ad hoc adhibitus interfui et scripsi et [sign]um meum apposui in testimonium veritatis quod est tale (+).

1292, outubro, 27

Preito entre os veciños das freguesías de Sanguiñeda e de Pereiras, dunha parte, e os do couto de Cans e de Liñar de Gundia, da outra, polos camiños e goridas deste último lugar que levaban ó monte de Vilardeola.

MADRID, $A H N$, 1455/8.- Perg. orixinal, 176x300 mm. Latín, gótica documental.

MADRID, $A H N$, Fondo monástico, Melón, Tumbo n. ${ }^{\circ} 325-\mathrm{B}$, fols. 356 v., 357 r. e v., copia simple. Con data equivocada de 17 de decembro.

[In Dei nomine, amen]. Sabeam todos como sub era de mille et CCC et triinta annos XXVII ${ }^{\mathrm{e}}$ dias de oytubro ante min Miguel Martines dicto da Veiga, juys de terra de Lourinna por Fernan Soares juys del rey en Toronno, os homees moradores da fliigisia de Sancta Maria de Sanginneda et da fliigesia de Sant Miguel de Pereyras querelaran et disseron que ellos avyam hussado et acostumado de iren con boys et con carros ao monte deo Vilardeola et de [pasar dende] desse monte para suas casas polos caminnos por que senpre usaran et acostumaran de [de ir] elles et seus entreçesores que foran ante dellos et de goareçeren desse monte por Linnar de Gundia que iaz en o cauto de Caens, et agora que achavan caminnos tapados et que os non leixavan por hy andar nen husar assy como os soyan de husar seus avoos et seus entreçesores [et os] outros homees que foran ante delles. Et eu por partir este preito? d'ontre estes homees destas dictas fliigisias de huna parte et os do cauto de Caens et de Linnar de Gundia et da outra parte, mandey chamar por pregon os homees das ditas fliigisias de Sanginneda et de Pereiras et chamey ante min frey Rodrigo frade do moesteyro de Santa Maria de Melon, morador ena granna de Caens et procurador do abbade et do convento do moesteyro sobredito et mandeylle que me apregoasse et chamasse os homes desse couto et os de Linnar de Gundia et que fossen an[te] min eese logar 
para saber o estado destes caminnos et as goaridas que os homees desas fliigisias et os outros que por i quisessen andar et goareçer avyan d'aver et por husse sempre estes camynnos husaran et acostumaran et por husse deçian desse monte para o rio de Louro. Et elles apregoados, chamey os homees mays ançianos et mayores de dias et pregunteilles quaes camynnos et quaes goaridas avieran por Linnar de Gundia seus avoos et aquelles que en aquestas fliigisias et eestas terras moravan, et elles diseron que o abbade et o convento do moesteyro de Santa Maria de Melon mandaran faser casaes en Linnar de Gundia et poblanças et mandaran lavrar pan et vinno et faser feyras. Et outrossy que mandaran faser casaes en Donicoes et en o Porrinno et deran estes caminnos et estas goaridas que fossen para sempre para estas terras sobreditas et para [o que] por elles quissesen andar. Primeyramente o caminno da Ponte de Naseyros et ende seu caminno para Pereyras et para Sanginneda et o outro camynno commo vay ao logar de Pedro Meendes et d'essy aos marcos de Pedro Gil, et d'essy por este carril contra o logar hu ora mora Pedro Fanon et des'i [como] se deçe ao porto do Ameeyrolongo et desy seu camynno para Saginneda et para Pereyras, et o outro caminno commo que deçe do dito monte et como ven ferir ao porto da moller et ende seu camynno para Petelos et para Barvadaens et para Sanginneda.

Et eu sobredito ouvy acordo et consello con homees boos sabedores do dereyto et segundo a verdade et a sabedoria que achey seendo ena seeda de julgar mando julgando por sentença de juyso que estes camynnos sobreditos seian sempre abertos? para goaridas destas ditas terras. Et outrossy mando julgando por sentença et por my so? que en o [couto] de Caens se algen quiser lavrar pan ou vinno ou faser outro lavor, que possa arredar o caminno mays afora por la sua herdade et desvyalo por outro logar dando todavya caminno et con consentimento do abbade et do convento sobredito ou daquelle que y estever por elles. Et outrossy mando que o dito abbade et convento ou a qualquer que y esteveren por elles en o dito couto que possan mudar et faser caminnos por aquelles logares que vyren que mays prol seera sua et do dito couto et dos homees que hy moraren et cada que llis ( $\mathrm{sic}$ ) mester for eese couto sobredito non fillando a nenguun os seus heredamentos. Et outrossy mando aos homees desse couto sobredito et o dito abbade et convento et os homees desse dito couto sobre que cabsar? esta razon non aian pena nenhuna, et desto lis ( sic) mandey dar esta carta que tenna en testemuya desta causa.

Testemuyas que foron presentes: Alvaro Martinez, Gonsalvo Laurenço, Pedro Miguelez clerigo, moradores en Pereyras Gonçalvo Rodrigues de Valadares, Garçia Eans clerigo de Petelos, Martin Martinez clerigo de Sanginneda, Johan Peres d’Eyroo, Laurenço Peres de Parada, Pedro Eans do Pumar, et outros.

Et eu Johan Peres notario publico jurado del rey en terra de Lourinna a esto presente fuy et esta carta por mandado do dito Miguel Martinez juyz por mia maao propria escrevy et meu sinal y puge que tal (signo) he.

1294, xaneiro, 31

O mosteiro de Melón afóralle a Pedro Martínez e á súa muller Elvira Paez unha devesa no couto de Cans no chouso da Graña.

MADRID, $A H N$, 1455/12.- Perg. orixinal, 200x160 mm. Galego, gótica documental. MADRID, AHN, Fondo monástico, Melón, Tumbo n. ${ }^{\circ} 325-\mathrm{B}$, fol. 355 v., copia simple.

[Conosçuda] cosa [seia] a quantos este plazo viren que eu frey Lourenço çelareiro do moesteyro de Sancta Maria de Melon [...] et do convento desse lugar a vos Pedro Martinez dito Guerra et a vossa moller Elvira Paez et a toda a vosa voz [...] nume do dito moesteyro dou 
a vos a foro huna devesa que o dito moesteyro a no couto de Caes no cho[uso da Granna...] eada? sobre cas Gonçinna Eans como parte do foro de Pedro Batalla et como parte do foro dos? [...] vai ferir o comaro? que chantou frey Fernando et vos et Lourenço Rodriguez et Johan Nunnez? do Rial et como parte por labaro? [...] de Gonçinna Eans do Rial et como parte por lo seu foro et como parte por la nossa devessa da Granna [...] desta devesa huun tallo de vinna de decimo a Deus que eu ei [...her]dade en que esta [...] et herdade jaz tralas casas que foron de meu irmao Johanne Martines como veay en testar en o regeengo da Granna et como vay ferir ante a porta hu morou Pedro Cambado. Et eu sobredito frey Lourenço en nume do dito moesteyro et do abade et do convento dou a vos a dita devesa por tal preito que dedes ende aa voz do dito moesteyro a terça et que lavredes a dita vinna et heredade que non defalesca por mingoa de lavor. Et de todo fruito que Deus y der dedes ende ao dito moesteyro a terça por seu ome et $\mathrm{a}[\ldots]$ por seu ome et qualquer das partes que contra esto quiser pasar aa outra parte que a gardar peyte por pena çinquenta moravedis et este plazo fique en sua revor valedeyro.

Feito o plazo postremeyro dia de janeiro era de mille et CCC.XXX et dous anos.

Ts que foron presentes: Pedro Mendiz de Linar de Gundia, Pedro Martinez pedreiro, Pedro Batalla, Fernan Vidal, Martin de Novegilde, Lourenço Fernan et outros.

Despoys desto Elvira Paez muller do sobredito Pedro Martinez outorgan[tes a este pla]zo na era sobredita [...] dias do mes de febreyro.

Ts que foron presentes: Johan Perez da Ponte, Pedro Alvo, Martin Ballan?, Pedro Ledo, Martin Ledo, Pedro Fernandez et outros.

Et eu Johan Perez [notario] publico [jurado en terra] de Lourinna desto presente fuy et por rogo das partes este plazo por minna [mao propria escrivi et meu] sinal y pugi [que tal he $(+)$ et en] mea preçencia [...]. Ts o dito frey Lourenço [...] do dito abade ena qual carta? o abade de Melon et convento [...] Lourenço [tal podese dar a foro] os herdamentos do dito moe[steyro...].

1297, febreiro, 3

O abade de Melón frei Pedro afóralle a Xoán Nunez e á súa muller María Eans, e ós seus fillos e ós seus netos, unha herdade no couto de Cans.

MADRID, AHN, 1456/5.- Perg. orixinal, 102×282 mm. Galego, gótica documental. MADRID, AHN, Fondo monástico, Melón, Tumbo n. ${ }^{\circ}$ 325-B, fols. 357 v. e 358 r., copia simple.

In Dei nomine, amen. Sabean [quantos este praço] viren et ovyren que? eu frey Pedro abbade de Mellon et o convento dese logar damos et outorgamos a foro a vos Johan Nunniz dito [...] et a vossa moller Maria Eans et a vosos fillos et a vossos netos a herdade que avemos en nosso couto de Caes nominada? conven a saber esa vinna que compramos de Fernan Garcia a que [...] essa careyra de Caes que vay por essa vila et parte de fondo do valado et eynda (sic) vos damos a terça da devessa da Escaarada et eynda vos damos a meadade do souto da devesa a qual fez Pura? Caa et Pedro Perez et eynda vos damos esses castineyros da Retorta que chantou Nunno Paaz, por tal preyto que vos lavredes bem et gardes essa herdade et essas castanas et essas devessas et profeytedes que non desfalesca por [...]. Et do fructo que Deus y der dedes ende ao mosteyro de Santa Maria de Mellon terca parte na heyra et na dorna et aas toras ( sic) das arvores por nosso ome et levar esa terca aa nossa grana de Caes por vosso custo et proveerdes de comer et de bever esse nosso omme que y por nos estever unna vez en un dia et seerdes nossos vasalos et se quiserdes vender vendede a nos et se nos non quisermos comprar vendede aa tal que a vos faza a foro en paz et se y fezerdes morada fazerdes a nos os foros que 
a nos fazem os omees do Porrinno et non [...] morar no noso couto [...] netos ficar a herdade a Santa Maria de Mellon asi como for mellorada sen outro embargo et a parte que isto $\mathrm{p}[\ldots]$ aa outra parte por pena $\mathrm{C}$ marabedis et o plazo seia firme.

Feyto o plazo tres dias de febreiro, era $\mathrm{M}^{\mathrm{a}}$.CCC ${ }^{\mathrm{a}}$.XXX ${ }^{\mathrm{a}}$ et $\mathrm{V}^{\mathrm{e}}$ anos.

Que foron presentes: frey Lourenço prior, Pedro Eans meestre dos frades, Juhan Martinez? monges que foy vestiaro, Martin Moogo de Sageas monges, Pedro Aanz monges, et todo o convento, Pedro Martin dito Penda, Martin carpenteyro, Johan [Perez carpenteyro] ts et outros.

Et eu Pedro Martinez notario jurado en terra de Lourinna por mandado de Johan Perez notario del rey en Toronno por rogo das partes este plazo por seu mandado escrivi et meu senal y pugy que est tal (+).

\section{ÍNDICE ONOMÁSTICO}

Inclúense neste índice a tódalas persoas mencionadas na documentación, ordenadas alfabeticamente seguindo unha orde de nomes propios e non de renomes ou patronímicos. Cada persoa clasificada acompáñase dun número ou números que corresponden ó do documento no que se mencionan.

A entrada dun nome cítase tal e como aparece no documento. Se existen variantes gráficas para unha mesma entrada, ten preferencia a máis habitual ou a máis completa, e é seguida entre parénteses das outras formas que aparecen na documentación. Esas variantes tamén teñen entrada, remitíndose á elixida como principal mediante un "vide".

Os nomes, patronímicos ou renomes transcritos con dúbida, que na edición se mostran en cursiva e acompañados do signo "?", consérvanse no índice, norma que tamén se aplica ás lagoas do texto.

Cando sexa posible os nomes acompañaranse de determinadas informacións que contribúan a identificar ó individuo, tales como o tratamento, as filiacións, os cargos ou a vecindade.

Reis, bispos, abades e tenentes cítanse polo súa forma actual, poñéndose a continuación entre parénteses os nomes tal e como aparecen na documentación.

[...] de Campos, 24.

[...] dito do Real, 24.

A., escribán, 7.

Afonso, (Adefonso), bispo de Ourense, 1 (1174, xuño, 25).

Afonso IX, (Afonso, Aldefonso), 6 (1223, marzo, 29), 7 (1223, marzo).

Afonso X, (Afonso, Alfonso), 14 (1252, novembro), 18, 19, 20, 21, 23, 24 (1274).
Afonso Petriz de Molin, frater, monxe de Melón, 3.

Alfonso Fernandez, 24.

Alfonso Iohannis, 13, marido de Marina Nuniz.

Alfonsus Michaelis, quondan canonicus auriensi et iudex delegatus a Domino Papa, 4.

Alfonsus Suerii de Fornelos, domnus, miles, 9.

Arias, escribán, 3.

Arias, presbiter de Urgillum, 6. 
Arie, frater, monxe de Melón, 11.

Alvaro Diaz de Barro, 3.

Alvaro Martinz, morador en Pereiras, 29.

Arias Garcie, converso de Melón, 6.

Bernal Eans, notario do rei en Toroño, 15.

Bernardo Martinz, 24.

Clemente: 8 ,

Didacus Didaci, escribán, 11.

Diego dicto Nouso, 24.

Dominicus Cresconet, 17.

Domingos, 15.

Dominicus, domnus, 10.

Dominicus Didaci, 13.

Domingo, frey, celareiro de Caes, 24.

Duran de Canalibus, 18.

Egidius Petri, miles, fillo de domnus Petrus Menendi dictus Feyioo, irmán de Iohannes Petri, marido de domna Eynes, 8, 9.

Elvira Nuniz, 14.

Elvira Paez, muller de Pedro Martinz dito Guerra, 30.

Estevo, (Estevo) don frey, abade de Melón, 27 (1288, xuño, 24)

Estevo Exea, (Stephanus), bispo de Tui, 6 (1223, marzo, 29), 7 (1223, marzo).

Eynes, muller de Egidius Petri, nora de domnus Petrus Menendi dictus Feyioo, cuñada de Iohannes Petri, 9.

Ferdinandus Agustin, 4.

Ferdinandus Nuni, 4.

Ferdinandus Petri, 22

Fernan Garcia, 31.

Fernan Nuniz, 19.

Fernan Paz, 24.

Fernan Porrino, 19.

Fernan Soares, xuíz do rei en Toroño, 29.

Fernan Vidal, 30.

Fernando dicto Corvo, 20.

Fernando II, 1 (1174, xuño, 25).

Fernando III, 9 (1231, maio, 19), 10, 15 (1252).

Fernando (Ferdinandus), frater, abbade de Melón, 22 (1260, abril).

Fernando, frater, 23.

Fernando, frey, 30.

Fernando Alfonsi, 11

Fernando Garcia de Ateos, 26.

Fernando Iohannis, (Fernando Iohannis, Ferdinando Iohannis), domno, tenente Limia/Toroño.- Tenente Limiam cum domno
Pelagio Arie, 9 (1231, maio, 19), 10 (1233, xaneiro, 9).- Tenente de Toroño, 14 (1252, novembro), 15, 18, 19, 20, 21, 23 (1264, xuño, 10).

Fernando Martinz, notario xurado en terra de Louriña, 25

Fernando Nunez do Rial de Caes, 24.

Fernando Petri dicto Porrino, 20, 22, 23.

Fernando Petriz, fillo de Pelagio Martinizi, 3.

Fernando Ponce, (Fernando Pontio), tenente Limia, 1 (1174, xuño, 25).

Fernando Varcia, morador das provanzas de Donicoes, 25.

Fernandus, celareiro de Melón, 5, 15.

Fernandus, frater, subprior de Melón, 6, 11, 13, 17.

Fernandus, vestiario de Melón, 13.

Fernandus Alfonsi de Donicoes, 13.

Fernandus Arie, frater apotegarius de Melón, 5.

Fernandus Burgensis, 10.

Fernandus Cabus, 5 .

Fernandus Calviis, 17.

Fernandus Calvus, prior de Melón, 9, 10.

Fernandus Calvus, 13.

Fernandus Faval, mordomo de Toroño, 15, 20, 21.

Fernandus Fernandi, 15.

Fernandus Fernandi de Burgo, vigairo do abade de Melón, 8.

Fernandus Menendi de Ambia, domnus, miles, 9. Fernandus Munionis, frater, converso de Melón, 6. Fernandus Petri de Medes, 5.

Fernandus Portella, 9.

Froya, domnus, 12, 15.

Gacia Fanon, 22

Garcia Pelagii, 7.

Garçia Eans, clerigo de Petelos, 29.

Garsia Petri, rectore ecclesie de Gudes, 28.

Gomecius, prior de Melón, 6.

Gómez, (Gomecius) abade de Melón, 9 (1231, maio, 19), 10 (1233, xaneiro, 9).

Gomez Crispus, 3.

Goncalvus, quid venit, 7

Gonçalvo Rodrigues de Valadares, 29.

Gonçinna Eans do Rial, 30.

Gondisalvus Fernandi, 23.

Gondissalvo Pelagii de Lira, 7.

Gonsalvo Laurenço, morador en Pereiras, 29.

Gonzalvo Eans de Fonteelo, 27

Gonzalvo Lopes, tenente as veces de Pedro Calzado notario publico en terra de Entenza e de Louriña, 24 
Gregorius, iuratus concilii auriensis, escribán, 9. Guncina Martini, muller de Iohannes Iohannis, 15. Gundisalvus, chantre de Melón, 13, 17.

Gundisalvus Mendi, xuíz real, 8.

Gundisalvus Larpote de Salvaterra, 18.

Gunsalvo Iohannis, capellano ecclesie Sancti Iacobi de R[ib]arteme, 28.

Ioanes, 3 .

Ioanes, fillo de domnus Menendus Abbas e domna Urraca, irmán de Petro, Velasco e domna Maior, 1.

Ioanes Arie, 8 , vide Iohannes Arie.

Ioanes Campisinus, 8 , vide Iohannes Campisinus. Ioanes de Hospicio, frater, 8.

Ioanes Fernandi, miles de Avelanedo, 8.

Ioanes Francum, quondan canonicus auriensi, iudex delegatus a Domino Papa, 4.

Ioanes Gomez Camundu, cuñado de Martino Petriz Alcrebado e de Roderigus Bacicryz, 3.

Ioanes Laurentius, regis vicarius, 8 .

Ioanes Munionis de Laureiro, 8.

Ioanes Petri, 4.

Ioannes, enfermeiro de Melón, 5.

Ioannes, monachus de Sancta Marta, 4.

Ioannes de Anote, notarius, 4.

Ioannes de Atenis, escribán, 5.

Ioannes Ferdinandi, notario Domini regis in Torono, 4 .

Iohannes, 7 .

Iohannes, abbade de Melón, 23 (1264, xuño, 10) .

Iohannes, escribán, 13, 14, 16, 17, 18.

Iohannes, servente de Martino Iohannis, 28.

Iohannes Arie, (Ioanes Arie), irmán de Petrus Arie e marido de Lupe Petri, 8, 9, 10.

Iohannes Balero de Caaes, 20.

Iohannes Campisinus, (Ioanes Campisinus), monxe de Melón, 8, 9.

Iohannes d'Alfaya, cunote de Martin Nuniz, 19. Iohannes Fanon, (Iohannes Fanion), 21, 23.

Iohannes Fernandi de Decia, domnus, miles, 9.

Iohannes Fernandi dictus de Montaos, 28.

Iohannes Garsie, milles de Lira, marido de Maria Suarii, 23.

Iohannes Guntin, 15.

Iohannes Iohanni, notario en terra de Louriña, 19, $20,21$.

Iohannes Iohannis, 17.

Iohannes Iohannis, celareiro de Melón, 9.

Iohannes Iohannis, marido de Guncina Martini, 15.
Iohannes Iohannis, marido de Maria Petri, 13. Iohannes Martini dicto Terciado de Salzeda, 21. Iohannes Martini, publico auriense notario, 28. Iohannes Menendi, 14. Iohannes Nunionis, 16. Iohannes Nuniz de Caes, 18. Iohannes Pelagii, 7. Iohannes Petri, 22.

Iohannes Petri de Burgo Avie, 9.

Iohannes Petri dictus Barreyro, clericus de Sancta Martha de Ligurin, 28.

Iohannes Petri, miles, fillo de domnus Petrus Menendi miles dictus Feyioo, irmán de Egidius Petri, cuñado de domna Eynes, 9.

Iohannes Petri, monachus, 12.

Iulianus, presbiter de Tauviga, 6 .

Johan Nunnez? do Rial, 30, vide Juan Nuniz do Real de Caes.

Johan Nunniz, marido de Maria Eans, 31.

Johan [Perez, carpenteyro], 31.

Johan Peres, 29, 30, vide Johan Perez.

Johan Peres d'Eyroo, 29.

Johan Perez, (Johan Peres), notario do rei en Louriña e en Toroño.- En Louriña, 29, 30.En Toroño, 31.

Johan Perez da Ponte, 30.

Johannes Martines, irmán de frei Lourenço, 30.

Johannes Peres, notario xurado en terra de Louriña, 15.

Juan [...], 24.

Juan Batalla, 24.

Juan Ferreiro, 25.

Juan Lourenzo, marido de Marina Eans, 27.

Juan Lourenzo, marido de Urraca Fernandez, 27. Juan Martinz, frey, prior de Melón, 27.

Juan Nuniz do Real de Caes, (Johan Nunnez? do Rial), 25, 30.

Juan Paaz, 25, vide Juan Paz.

Juan Paz, (Juan Paaz), 24, 25.

Juan Pelaez, 26.

Juan Soarez, cabaleiro de Atios, 26.

Juhan Martinz?, monxe que foi vestiaro de Melón, 31.

Laurenço Peres de Parada, 29.

Laurentius Ioannis, clericus rector ecclesie Sante Eulalie de Ateos, 4.

Laurentius Martini, frater, monachus Melonis, 4. Laurentio Ordonii, 28.

Lorenzo de [...], frey, 27.

Lourenço, frey, celareiro de Melón, 30. 
Lourenço, frey, prior de Melón, 31.

Lourenço Fernan, 30.

Lourenço Rodriguez, 30.

Lourenzo, (Laurentio) bispo de Ourense, 9 (1231, maio, 19), 10 (1233, xaneiro, 9).

Lupe Petri, muller de Iohannes Arie, 10.

Maior, domna, filla de domnus Menendus Abbas e domna Urraca, irmá de Petro, Ioanes e Velasco, 1.

Maior Menendi, 14.

Maior Pelagii, 7.

Maiori Petri, muller de Petro Iohannis, 15.

Maior Salvadorit, nai de Maria Iohannis, 18.

Maria de Dei de Barrio, nai de Petrus Petri, 20.

Maria Eans, muller de Johan Nunniz, 31.

Maria Gonsalvit, irmá de Marina Gonsalvit, 19.

Maria Iohannis, filla de Maior Salvadorit, 18.

Maria Iohannis, muller de Martino Dominici, 15.

Maria Martinz, filla de Miguel Eans, muller de Martin Paz dito Rata, 24.

Maria Menendi, 14.

Maria Pelagii, 7.

Maria Petri, muller de Iohannes Iohannis, 13.

Maria Petriz, muller Pelagius Pelaiz de Athenus, 2.

Maria Suarii, muller de Iohannis Garsie, 23.

Marina Eans, muller de Juan Lourenzo, 27.

Marina Gonsalvit, irmá de Maria Gonsalvit, 19.

Marina Martini, 17.

Marina Nuniz, muller de Alfonso Iohannis, 13.

Martín, (Martinus), dominus, abade de Melón, 1

(1174, xuño, 25), 3 (1185), como escribán 1, 2.

Martin, carpenteyro, 31.

Martin Ballan?, 30.

Martin de Novegilde, 30.

Martin Fernandez, 27.

Martin Gomez, 27.

Martin Ledo, 30.

Martin Martinz, clerigo de Sanginneda, 29.

Martin Moogo de Sageas, monxe de Melón, 31.

Martin Nuniz, cunote de Iohanne d'Alfaya, 19.

Martin Nuniz de Porrino, (Martinus Nuniz de Porrino), 22, 26.

Martin Paz dito Rata, marido de Maria Martinz, xenro de Miguel Eans, 24.

Martín Sánchez (Martino Sancii), domno, tenente Turiam/castelo de Entenza, 6 (1223, marzo, 29), 7 (1223, marzo).

Martino, 11.

Martino dicto Corvo, 20.
Martino Dominici, marido de Maria Iohannis, 15.

Martino Iohannis, perticario auriense, 28.

Martino Laurencio de Doniquees, 14.

Martino Pelagii, 7.

Martino Petriz Alcrebado, cuñado de Roderigus Bacicryz e de Ioanes Gomez Camundu, neto de Suerius Nigret, 3.

Martinus, celareiro de Toroño, 17.

Martinus, irmán de Rodericus, 3.

Martinus, prior de Melón, 11, 13.

Martinus Batel, 18.

Martinus Froile, miles, clericus, 6.

Martinus Iohannis, monxe de Melón, 9.

Martinus Iohannis, notario en Louriña, 22, 23.

Martinus Martini de Viso, 18.

Martinus Moogo dictus Guerra, rector de Santa María de Sanguiñeda, 4.

Martinus Nuniz de Porrino, 22, vide Martin Nuniz de Porrino.

Mayor Menendi, 14.

Mendus Salvatoriz, fideiussor, 7.

Menendus Abbas, domnus, esposo de domna Urraca e pai de Petro, Ioanes, Velasco e domna Maior, 1.

Menendus Alvari, 8.

Menendus Arie, monxe de Melón, 6.

Menendo Pelagii, 7.

Michael, apotacarius de Melón, 6.

Miguel Eans, pai de Maria de Martinz, sogro de Martin Paz dito Rata, 24.

Miguel Martines dicto da Veiga, xuíz de terra de Louriña, 29.

Monio, frater, celareiro de Melón, 19.

Munio, celareiro de Toroño, 16.

Munio Fernandi, 10.

Munio Ianeiro, 8.

Munio Petri, 10.

Munione Fernandi, maiorino regi, 15.

N., 3.

Nonus Velascus, 10.

Nudu Midiz, 3.

Nunno Paaz, 31.

Nunnus, 3.

Nunnus Iohannis de Canes, 22.

Nunnus Petri, monxe de Melón, 11.

Nuno, fratri, celareiro de Melón, 22.

Nuno Fernandez, 4.

Nuno Fernandi de Belmonti, miles, 9.

Nuno Fernandi dito Pato, morador das provanzas de Donicoes, 25. 
Nuno Iohannis de Donicones, 21.

Nuno Martini, 12.

Nuno Martinz, 24.

Nuno Pato, 26.

Nuno Petri Curvo, 12.

Nunus, 2, 3 .

Nunus, ausenti, 23.

Nunus Iohannis de Novigilde, 13.

Nunus Petri, clericus de Nugeira, 12.

Nunus Petri, fillo de Petrus Alvus, irmán de Petrus Petri, 5.

Orrace Pelagii, 7.

Paay Johannes, 25.

Paio Arias (Pelagio Arie), tenente Limiam cum domno Fernando Iohannis, 9 (1231, maio, 19), 10 (1233, xaneiro, 9).

Pasqual Eans, fillo de Juan Ferreiro, 25.

Pedro (Petrus), domnus, abade de Melón, 4 (1189, febreiro, 24).

Pedro (Petro), 5 (1219, agosto).

Pedro (Petrus), domnus, abade de Melón, 11 (1245, xuño, 23), 12, 13, 15, 16, 17, 20, 21 (1256).

Pedro, (Pedro), don, abade de Melón, 26 (1287, xuño, 15).

Pedro, (Pedro, Petrus), don, abade de Melón, 28 (1289, xullo, 29), 31 (1297, febreiro, 3).

Pedro Aanz, monxe de Melón, 31.

Pedro Alvo, 19, 30.

Pedro Batalla, 30.

Pedro Cambado, 30.

Pedro Calzado, notario publico en terra de Entenza e de Louriña, 24.

Pedro Corvo, 24.

Pedro Eans, mestre dos frades de Melón, 31.

Pedro Eans de Campos, 24.

Pedro Eans do Pumar, 29.

Pedro Fanon, 29.

Pedro Fernandez, 30.

Pedro Gil, 29.

Pedro Ledo, 30.

Pedro Lourenzo, tenente as veces [...], 24.

Pedro Martin dito Penda, 31.

Pedro Martinz, pedreiro, 30.

Pedro Martinz, (Petrus Martinz), notario xurado en terra de Louriña, 22, 26, 31.

Pedro Martinz de Porrino, 26.

Pedro Martinz dito Guerra, marido de Elvira Paez, 30.

Pedro Meendes, 29.
Pedro Mendez de Ardegunda, 24.

Pedro Mendiz de Linar de Gundia, 30.

Pedro Miguelez, crego, morador en Pereiras, 29.

Pedro Miguelez de Valadares, 24.

Pedro Perez, 31.

Pelagio dos Ovos, mordomo de Martino Sancii, 7.

Pelagio Fernandiz nominato N[...]bos, 7.

Pelagio Maraniom, fideiussor, 7.

Pelagio Martinizi, pai de Fernando Petriz, 3.

Pelagio Pelagii, 7.

Pelagius, $3,7$.

Pelagius, escribán, 10.

Pelagius, frater, monxe de Melón, 11.

Pelagius de Canis, frater, 13.

Pelagius Iohannis de Campos, 13, 22.

Pelagius Iohannis de Donicones, 21.

Pelagius Pelaiz de Athenus, marido de Maria Petriz, 2.

Petro, fillo de domnus Menendus Abbas e domna Urraca, irmán de Ioane, Velasco e domna Maior, 1.

Petro Calvo de Villis, 23.

Petro Chouteiro, 20.

Petro Crispo, domino, 3.

Petro do Baal, mordomo en Louriña, 19, 20.

Petro Iohannis, marido de Maior Petri, 15.

Petro Moogo, 16, vide Petrus Moogo.

Petro Osso, 16.

Petro Petri, 28, vide Petrus Petri, fillo de Petrus Alvus.

Petro Porrino, 19.

Petro Seco, 19.

Petrus, 2, 3, 7.

Petrus, enfermeiro de Melón, 17.

Petrus, escribán, 15.

Petrus, prior de Melón, 5, 15, 17.

Petrus, sacristán de Melón, 5.

Petrus, subenfermeiro de Melón, 6.

Petrus, subprior de Melón, 15.

Petrus Albus, 5, 7, vide Petrus Alvus.

Petrus Alvus ( Petrus Albus), clericus de Santa Marta, pai de Petrus Petri e Nunus Petri, 5, 7, 12,28 .

Petrus Arie, mordomo, irmán de Iohannes Arie, 8, 9, 10.

Petrus Azar, miles, 9.

Petrus Coronatus, 3 .

Petrus Cultello, 12.

Petrus Cupino, 15 .

Petrus de Barrio, 23.

Petrus Didaci, 12. 
Petrus Garsie de Fornelos, domnus, miles, 9.

Petrus Guiladi, clericus, 6.

Petrus Ioannis, monachus Melonis, 4.

Petrus Martini de Teelas, 18.

Petrus Martinz, 22, vide Pedro Martinz.

Petrus Maurus de Portu, 8.

Petrus Menendi, 10, 14.

Petrus Menendi dictus Feyioo, milite, pai de Egidius Petri e de Iohannes Petri, sogro de domna Eynes, 9.

Petrus Moogo Rabicio, (Petro Moogo), 14, 16.

Petrus Nariz de Fornelos, miles, 9.

Petrus Nuni dicto Cornuto, 21

Petrus Nunioni, subprior de Melón, 10.

Petrus Nunionis, 16

Petrus Nuniz, 14.

Petrus Pelagii, 7

Petrus Petri, 10, 12.

Petrus Petri, fillo de Maria de Dei de Barrio, 20.

Petrus Petri, (Petro Petri), fillo de Petrus Alvus, irmán de Nunus Petri, 5, 28.

Petrus Petri dicto Allote de Sangueneda, 14.

Petrus Ramirit, porteiro de Melón, 6.

Petrus Roderici, monxe de Melón, 9.

Petrus Ruderici, 10.

Petrus Telas, 10.

Pura? Caa, 31.

Rama Pelagii, 7.

Roderico Iohannis, clericus chori auriense, 28.

Roderico Roderici, archidiacono de Baroncelle, 28.

Rodericus, irmán de Martinus, 3.

Rodericus, sochantre de Melón, 17.

Rodericus, vestiario de Melón, 5, 15, 17.

Rodericus Froile, 8.

Rodericus Guntin, 15.

Rodericus Ioanis, vicarii regis, 8 .

Rodericus Martini, 13, 17.

Rodericus Martini, contralorum (sic) de Melón, 5.

Rodericus Martini, subnotarius iuratus de Martinus Iohannis, 23.

Rodericus Martini de Aliariz, 9.

Rodericus Passaro de Rovoredo, miles, 9.
Rodericus Petri, 12, 13

Rodericus Suariz, meiriño maior en Galicia, 19.

Roderigus Bacicryz, cuñado de Martino Petriz Alcrebado e de Ioanes Gomez Camundu, 3.

Rodrigo, frey, frade de Melón, morador na granxa de Cans e procurador de Melón, 29.

Ruderico Pelagii, 7.

Sanchio Pelagii, meiriño rexio, 10.

Sancia Pelagii, 7.

Salvador Froile, 8.

Salvator Pelagii, 7.

Salvatori Petri, 16.

Stefanus Fernandi, miles, 8 .

Suerio Pelagii, 7.

Suerius, 2.

Suerius Nigret, avó de Martino Petriz Alcrebado, 3.

Symeon Alvarz, 7

Tomas Fanion, 23.

Urraca, domna, muller de domnus Menendus Abbas, nai de Petro, Ioanes, Velasco e domna Maior, 1.

Urraca Fernandez, muller de Juan Lourenzo, 27. Urraca Gomit, 6.

V., dominum, quondam cantorem auriense, 4 .

V. Roderici, domno, archidiacono de Baroncelle, 4.

Velasco, fillo de domnus Menendus Abbas e domna Urraca, irmán de Petro, Ioanes e domna Maior, 1.

Velascus, vestiario de Melón, 8, 9.

Velascus Menendi, miles, 9.

Velascus Nuni de Aliariz, 9.

Velascus Saccus, 8.

Vermudo, domno, abade de Melón, 6 (1223, marzo, 29)

Xil Pérez de Cerveira, (Egidio), bispo de Tui, 14 (1252, novembro), 15, 18, 19, 20, 21, 23 (1264, xuño, 10)

Xoán Fernández (Juan Fernandez), tenente Toronio, 24 (1274). 


\section{ÍNDICE TOPONÍMICO}

Os nomes que se ofrecen neste índice aparecen por orde alfabética, tanto os nomes oficiais actuais coma as súas variantes antigas ou non oficiais. Estes nomes van seguidos dun número ou números que se corresponden co documento ou documentos nos que se atopou o topónimo.

Os nomes oficiais actuais preséntanse en letras versais, e é esta denominación á que se remite, tanto no caso de nomes antigos coincidentes cos oficiais actuais como no caso das variantes antigas e non oficiais, agás nos casos nos que non se puideron localizar.

A continuación do nome oficial actual ofrécense entre parénteses as variantes gráficas dese topónimo citadas na documentación, e despois da súa localización (na que se sinalará a parroquia, o concello e a provincia actual), os números de tódolos documentos nos que tal topónimo sexa citado, independentemente da grafía na que apareza escrito. Esas variantes tamén teñen entrada, remitíndose á elixida como principal mediante un "vide".

No caso dos topónimos non conservados na actualidade pero que si puideron ser localizados documentalmente, estes aparecerán en cursiva, e se procederá a ofrece-la información do mesmo xeito ca no caso dos nomes oficiais actuais.

En canto ós renomes toponímicos optouse por non especificar o nome de cada individuo e ofrecelos coa mención xenérica "N. de", seguido do topónimo en cuestión.

Para a localización dos topónimos tívose en conta a información que ofrecen os propios documentos e o Nomenclátor de Galicia, citado na bibliografía.

Agro de Canpos, hereditatem que vocitat, 18. Alfaya, N. d', 19.

Aliariz, N. de, 9, vide ALLARIZ.

ALLARIZ.- (Aliariz).- Concello, vila e parroquias de Santiago e Santo Estevo.- Concello de Allariz. Provincia de OU.- 9.

Ambia, N. de, 9.

Ameeyrolongo, porto do, 29, vide AMEIRO LONGO. AMEIRO LONGO, lugar de.- (Ameeyrolongo).Parroquia de Santa María de Sanguiñeda. Concello de Mos. Provincia de PO.- 29.

Anote, N. de, 4.

Antencia, tenente castello, 7, vide ENTENZA, terra de/castelo.

Antenza, notario del rey en terra d', 24, vide ENTENZA, terra de/castelo.

Arais, 6.

Ardegunda, N. de, 24. Podería ser un erro do amanuense por Liñar de Gunda.
ARNOSO, San Lourenzo de.- (Arnuso).- Parroquia.Concello de Ponteareas. Provincia de PO.- 6. Arnusu, 6, vide ARNOSO, San Lourenzo de.

ASTURIAS.- (Asturias).- Rexión histórica e comunidade autónoma de España; título de soberanía da Coroa de España asociado ó Heredeiro, 7.

Asturias, rege regnante in, 7, vide ASTURIAS. Atenis, N. de, 5, vide ATIOS, Santa Eulalia de. Ateos, ecclesie Sante Eulalie de, 4, vide ATIOS, Santa Eulalia de.

Ateos, filigresia Sancte Eolalie de, 28, vide ATIOS, Santa Eulalia de.

Ateos, N. de, 26, vide ATIos, Santa Eulalia de. Athenus, N. de, 2, vide ATIOS, Santa Eulalia de. ATIOS, Santa Eulalia de.- (Athenus, Atenis, Ateos, Sancte Eolalie de Ateos, Sante Eulalie de Ateos).- Parroquia.- Concello de O Porriño. Provincia de PO.- 2, 4, 5, 26, 28. 
Auria, episcopus in, 9, 10, vide OURENSE.

Aurie, 28, vide OURENSE.

Auriense, clericus chori, 28, vide OURENSE.

Auriense, perticario, 28, vide OURENSE.

Auriense, publico notario, 28, vide OURENSE.

Auriensi, ecclesia, 4, 28, vide OURENSE.

Auriensi, episcopo in sede, 1 , vide OURENSE.

Auriensis, canonicos, 4, vide ourEnSE.

Auriensis, concilii, 9, vide OURENSE.

Avelanedo, N. de, 8.

Baal, N. de, 19, 20.

Baroncelle, archidiacono de, 4, vide BARONCELLE. BARONCELLE, lugar de.- (Baroncelle, Baronçelli).

Parroquia de Santo Estevo de Carboentes. Concello de Rodeiro. Provincia de PO.

Baronçelli, archidiacono de, 28, vide BARONCELLE.

Barrio, hereditatis de, 23.-[In Donicoes et in couto de Caes].- Parroquia de Santo Estevo de Cans. Concello de O Porriño.- 3, 20, 21, 23.

Barrio, N. de, 20, 23, vide Barrio, hereditatis de.

Barro, hereditate de, 21, vide Barrio, hereditatis de.

Barro, N. de, 3, vide Barrio, hereditatis de.

Barvadaens, 29.

Barvetha, 2.

Belmonti, N. de, 9.

Bouça Camposa, souto da, 15.

Burgo, N. de, 8.

Burgo Avie, N. de, 9.

Caas, 27, vide CANS, Santo Estevo de.

Caas, casares de, 27, vide CANS, Santo Estevo de. Caaes, N. de, 20, vide Cans, Santo Estevo de.

Caens, cauto de, 29, vide CANS, Santo Estevo de.

Caens, granna de, 29, vide CANs, Santo Estevo de.

Caes, 25, 31, vide Cans, Santo Estevo de.

Caes, celareiro de, 24, vide CANS, Santo Estevo de.

Caes, couto de, 23, 24, 30, 31, vide CANS, Santo

Estevo de.

Caes, graña de, 25, 27, 31, vide CANS, Santo Estevo de.

Caes, N. de, 18, vide Cans, Santo Estevo de.

Caes, N. do Real de, 25, vide Cans, Santo Estevo de.

Caes, N. do Rial de, 24, vide Cans, Santo Estevo de.

Campis, hereditatem de, 14.

Campos, N. de, 13, 22, 24.

Canales, cauto de, 28, vide CANS, Santo Estevo de.

Canales, monte de, 3, vide CAns, Santo Estevo de.

Canalibus, 5, 17, vide CANS, Santo Estevo de.

Canalibus, cauto de, 4, 17, vide CANS, Santo Estevo de.
Canalibus, cellarium de, 16, vide CANS, Santo Estevo de.

Canalibus, N. de, 18, vide CANS, Santo Estevo de.

Canalibus, termino de, 5, vide CANS, Santo Estevo de.

Canalis, hominum de, 11, vide CANS, Santo Estevo de.

Candaosa, hereditatem de, 12.

Canenes, 22. Podería ser un erro do amanuense por Canes.

Canes, 12, vide CANS, Santo Estevo de.

Canes, cellarium de, 15, vide CANS, Santo Estevo de.

Canes, N. de, 22, vide Cans, Santo Estevo de.

Canis, N. de, 13, vide CANs, Santo Estevo de.

Cans, graña de, 27, vide CANS, Santo Estevo de.

CAns, Santo Estevo de.- (Caas, Caaes, Caens, Caes, Canales, Canalibus, Canalis, Canes, Canis, Cans, Cays, Real de Caes, Rial de Caes).Parroquia.- Concello de O Porriño. Provincia de PO.- 3, 4, 5, 7, 11, 12, 13, 15, 16, 17, 18, 20, 22, 23, 24, 25, 27, 28, 29, 30, 31 .

CASTElA.- (Castella, Castilla).- Antigo reino hispánico.- 9, 10, 14, 15, 18, 19, 20, 21, 24.

Castella, rex in, 9, 10, 14, 15, 18, 19, 20, 21, 24, vide CASTELA.

Castenaria, loco que vocatur, 16.

Castilla, reinando en, 24, vide CASTELA.

Castro de Fonteelo, monte, 19, vide CASTRO, o.

CAstro, o, lugar de.- (Castro de Fonteelo).Parroquia de Santa Eulalia de Atios. Concello de O Porriño.- Provincia de PO.- 19.

Cays, termino de, 7, vide CANs, Santo Estevo de. Cima, agro da, 24.

CÓRDOBA.- (Corduba).- Cidade, bispado e provincia da rexión de Andalucía; título de soberanía da Coroa de España, 15.

Corduba, regnante in, 15, vide CóRDOBA.

Cristobail, 3 .

Cristovail, 2.

Cristovail, hereditate de, 3 .

Decia, N. de, 9.

Donicoes.- (Donicoes, Donicones, Donicoys, Doniquees, Dunicoes).- Lugar hoxe non identificado, pero documentado no concello de O Porriño. Provincia de PO.- 3, 11, 13, 14, 20, 21, 22, 23, 25, 29.

Donicoes, casaes en, 29, vide Donicoes.

Donicoes, hereditate in, 23, vide Donicoes.

Donicoes, N. de, 13, vide Donicoes.

Donicoes, provanzas de, 25, vide Donicoes.

Donicones, 22, vide Donicoes. 
Donicones, hereditate de, 20, vide Donicoes.

Donicones, N. de, 21, vide Donicoes.

Donicoys, leira de, 11, vide Donicoes.

Doniquees, N. de, 14, vide Donicoes.

Dunicoes, hereditatem in, 3 , vide Donicoes.

Enfensta, hereditatem de, 13.

Enfesta, 13.

ENTENZA, terra de/castelo.- Comarca histórica do sur da provincia de PO con cabeceira en Salceda de Caselas.- 7, 24.

Escaarada, devessa da, 31.

Escaarada, porto da, 15.

Eyroo, N. de 29.

Fiscaniis, hereditate de, 11.

Fonteelo, Castro de, monte, 19, vide Fontelo.

Fonteelo, cavada de, 21, vide Fontelo.

Fonteelo, hereditate de, 15, vide Fontelo.

Fonteelo, lugares de, 27, vide Fontelo.

Fonteelo, N. de, 27, vide Fontelo.

Fonteelo, regeyro de, 15, vide Fontelo.

Fontelo.- (Castro de Fonteelo, Fonteelo, Fontenlo). Lugar hoxe non identificado, pero documentado na parroquia de Santa Eulalia de Atios. Concello de O Porriño. Provincia de PO.- 15, 19, 21, 27.

Fontenlo, casal de, 27, vide Fontelo.

Fornelos, N. de, 9.

Galicia.- (Gallecia).- Rexión histórica, reino hispánico, título de soberanía da Coroa de España.- 7, 19.

Galifaes, 16.

Gallecia, 7, rege in, vide GALICIA.

Gallecia, meirino mayori in, 19, vide GALICIA.

Granna, chouso da, 30, vide GRAÑA, A.

Granna, devessa da, 30, vide GRAÑA, A.

Granna, regeengo da, 30, vide GRAÑA, A.

GRAÑA, A, lugar de.- Parroquia de San Estevo de Cans. Concello de O Porriño. Provincia de PO.- 30 .

Gudes, lugar de.- Parroquia de San Xoan de Guntimil. Concello de Xinzo de Limia. Provincia de OU.- 28.

Gudes, rectore ecclesie de, 28, vide GUDES.

Laureiro, N. de, 8.

Laurina, maiordomo in, 19, vide LOURIÑA, Val da. Laurina, notario en terra de, 23, 24, 26, vide LOURIÑA, Val da.

Laurinae, notarius, 22, vide LOURIÑA, Val da.
Legione, rex in, 6, 9, 10, 14, 15, 18, 19, 20, 21, 23, 24 , vide LEÓN.

Legionem, regnante in, 7, vide LEÓN.

LEÓN.- (Legione, Legionem, Leon).- Provincia, cidade, bispado, concello e rexión histórica; antigo reino hispánico; título de soberanía da Coroa de España.- 6, 7, 9, 10, 14, 15, 18, 19, 20, 21, 23, 24.

Leon, reinando en, 24, vide LEÓN.

Lignar de Gundia, loco qui dicitur, 28, vide Liñar de Gundia.

Ligurin, Sancta Martha de, 28.

Limia, tenente, 1, 10, vide LIMIA, terra de.

LIMIA, terra de.- (Limia, Limiam, Limie).- Antiga terra xurisdiccional, sita no sector suroccidental da provincia de OU que ven a coincidir en xeral coa actual comarca da Limia.- 1, 9, 10, 28.

Limiam, tenente, 9, vide LIMIA, terra de.

Limie, archidiacattus, 28, vide LIMIA, terra de.

Linar de Gunda, loco qui dicitur, 5, vide Liñar de Gundia.

Linar de Gundi, heredamento en, 26, vide Liñar de Gundia.

Linar de Gundia, loco nominato, 7, vide Liñar de Gundia.

Linar de Gundia, N. de, 30, vide Liñar de Gundia.

Linare, 7, vide Liñar de Gundia.

Linare de Gunda, 7, vide Liñar de Gundia.

Linnar de Gundia, 29, vide Liñar de Gundia.

Liñar de Gundia.- (Linar de Gunda, Linar de Gundi, Linar de Gundia, Linare, Linare de Gunda, Lignar de Gundia, Linnar de Gundia).- Lugar hoxe non identificado pero documentado no termo de Cans, na fregresía de Santa Eulalia de Atios. Concello de O Porriño. Provincia de PO.- 5, 7, 26, 28, 29, 30.

Lira, milles de, 23.

Lira, N. de, 7.

Lor, río de, 7, vide Louro.

Lourina, notarius in terra de, 19, 20, 21, 25, vide LOURIÑA, Val da.

Lourinna, juys de terra de, 29, vide LOURIÑA, Val da.

Lourinna, notario en terra de, 15, 29, 30, 31, vide LOURIÑA, Val da.

LOURIÑA, Val da.- (Laurina, Laurinae, Lourina, Lourinna, ).- Comarca histórica do sur da provincia de PO que abarca os actuais concellos de Mos e de O Porriño, con cabeceira neste último.- $15,19,20,21,22,23$, $24,25,26,29,30,31$. 
LOURO, río.- Afluente do río Miño que descorre polos municipios de Pazos de Borbén, Mos, Redondela, Porriño e Tui.- 7, 29.

Louro, río de, 29, vide LOURO.

Medes, N. de, 5.

Melon, abade/convento/mosteiro de, 2, 3, 5, 6, 8, 13, 18, 20, 21, 26, 28, 30, vide MELón, Santa María de.

Melon, abade/convento/mosteiro de Sancte Marie de, 1, 9, vide melón, Santa María de.

Melon, abade/convento/mosteiro de Santa Maria de, 24, 25, 27, 29, vide MELón, Santa María de.

Melon, celararius de, 22, vide MELón, Santa María de. Melon, prior de, 9, vide Melón, Santa María de. MELón, Santa María de.- (Melon, Melone, Melonis, Mellon, Mellone, Sancta Maria de Melon, Sancte Marie de Melon, Sancte Marie Melonis, Santa Maria de Melon, Santa Maria de Mellon, Sante Marie de Mellon).Concello, parroquia, lugar e antigo mosteiro cisterciense masculino de Santa María.Concello de Melón. Provincia de OU.- 1, 2, 3 , $4,5,6,8,9,10,11,12,13,15,16,17,18,19$, $20,21,22,23,24,25,26,27,28,29,30,31$.

Melone, abade/convento de, 3, 10, 15, vide MELón, Santa María de.

Melonis, abade/convento de, 11, 16, 17, 22, 23, vide MELón, Santa María de.

Melonis, capitulo, 10, vide MELón, Santa María de.

Melonis, celareiro, 19, vide MELón, Santa María de.

Melonis, monasterium Sancte Marie, 12, vide MELón, Santa María de.

Montaos, N. de, 28.

Molin, N. de, 3 .

Naseyros, ponte de, 29.

Novigilde, N. de, 13.

Novegilde, N. de, 30.

Nugeira, N. de, 12.

Ourense.- (Auria, Aurie, Auriense, Auriensi, Auriensis).- Cidade, bispado, concello e provincia.- 4, 9, 10, 28.

Parada, N. de, 29.

Peraria, leira de, 11, vide PEREIRAS, San Miguel de. Perariis, hereditatem de, 8, vide PEREIRAS, San Miguel de.

Pereiras, fliigisia de, 29, vide PEREIRAS, San Miguel de.

Pereiras, hereditatem de, 1, vide PEREIRAS, San Miguel de.
PEREIRAS, San Miguel de.- (Peraria, Perariis, Pereiras, Pereyras, Sant Miguel de Pereyras, Sancti Michaelis de Pireiras).- Parroquia.- Concello de Mos. Provincia de PO. 1, 8, 9, 10, 11, 12, 29.

Pereiras, termino de, 10 , vide PEREIRAS, San Miguel de.

Pereyras, fliigesia de Sant Miguel de, 29, vide PEREIRAS, San Miguel de.

Pereyras, moradores en, 29, vide PEREIRAS, San Miguel de.

Pereyras, villa que vocatur, 9, vide PEREIRAS, San Miguel de.

Pireiras, ecclesia Sancti Michaelis de, 12, vide PEREIRAS, San Miguel de.

PETElos, San Mamede de.- (Petelos).- Parroquia.Concello de Mos. Provincia de PO. 29.

Petelos, 29, vide PEtelos, San Mamede de.

Ponte, N. da, 30.

Ponte de Naseyros, 29.

Porrinno, casaes eno, 29, vide PORRIÑO, O

Porrinno, omees do, 31, vide PORRIÑO, o

Porrino, alcume/apelido, 19, 20, 22.

Porrino, N. de, 22, 23, 26, vide PORRIÑO, O

PORRIÑO, O.- (Porrinno, Porrino).- Concello, vila e parroquia de Santa María.- Provincia de PO.19, 20, 22, 23, 26, 29, 31.

Porto, 7.

Portu, N. de, 8 .

Pumar, N. de, 29.

Real de Caes, N. de, 25, vide RIAL, O.

Real, N. do, 24, vide RIAL, O.

Retorta, 31.

Rial de Caes, N. de, 24, vide RIAL, O.

Rial, N. de, 30, vide RIAL, O.

RIAL, O, lugar de.- (Real, Real de Caes, Rial, Rial de Caes).- Parroquia de Santa Eulalia de Atios. Concello de Mos. Provincia de PO.- 24, 25, 30.

Ribarteme, capellano ecclesie Sancti Iacobi de, 28 , vide RIBARTEME, Santiago de.

RIBARTEME, Santiago de.- (Sancti Iacobi de Ribarteme).- Parroquia.- Concello de As Neves. Provincia de PO. 28.

Rovoredo, N. de 9.

Sageas, N. de, 31 .

SALCEDA DE CASELAS.- (Salzeda).- Concello, vila e parroquias de San Xurxo e Santa María.Provincia de PO.- 21.

SALVATERRA DE MIÑO.- (Salvaterra).- Concello, vila e parroquia de San Lourenzo. Provincia de PO.- 18 . 
Salvaterra, N. de, 18, vide SALVATERRA DE MIÑO.

Salzeda, Terciado de, N. de, 21, vide SALCEDA DE CASELAS.

Sangineda, rectorem Sante Marie de, 4, vide SANGUIÑEDA.

Sanginneda, fliigisia de Sancta Maria de, 29, vide SANGUIÑEDA.

Sangueneda, N. de, 14, vide SANGUIÑEDA.

SANGuiÑEDA, Santa María de (Sancta Maria de Sanginneda, Sante Marie de Sangineda, Sangueneda).- Parroquia.- Concello de Mos. Provincia de PO.- 4, 14, 29.

Sancta Marta, clericus/monachi de, 4, 28, vide SANTA MARTA.

Sancta Marta, N. de, 12, vide SANTA MARTA.

Sancta Marta, termino de, 7 , vide SANTA MARTA.

Sancta Martha de Ligurin, 28, vide SANTA MARTA. Sancto Laurentio, 6.

Santa Marta, clericus de, 5, vide SANTA MARTA. SANTA MARTA, lugar de e antiga parroquia.- (Sancta Marta, Santa Marta).- Parroquia de Santa Eulalia de Mos. Concello de Mos. Provincia de PO.- 4, 5, 7, 28.

SEvilla.- (Sibila, Sibilia, Sibillia).- Cidade, concello, arcebispado e provincia da rexión de Andalucía; título de soberanía da Coroa de España.- 15, 18, 19.

Sibila, regnante in, 15 , vide SEVILLA.

Sibilia, rege in, 18, vide SEVILLA.

Sibillia, rege in, 19, vide SEVILLA.

Tauviga, presbiter de, 6 .

Teelas, N. de, 18.
TOLEDO.- (Tolleto).- Cidade, concello, arcebispado e provincia da rexión histórica de Castela A Nova; título de soberanía da Coroa de España.- 15.

Tolleto, regnante in, 15, vide TOLEDO.

Toronio, cellararius de, 17, 16,vide Toroño.

Toronio, tenente terra de, 15, 18, 23, 24, vide Toroño.

Toronno, juys del rey en, 29, vide Toroño.

Toronno, notario del rey en, 15, 31, vide Toroño.

Torono, notario Domino regis in, 4, vide Toroño.

Toroño.- (Toronio, Toronno, Torono).- Antiga terra medieval que a moi grandes riscos abarcaría o territorio da diocese de Tui.- 4, 15, 16, 17, $18,29,31$.

Tuda, episcopo in, 6, 7, 14, 15, 18, 19, 20, 21, 23, vide TUI.

Tudensis, diocesis, 4, 28, vide TUI.

TUI.- (Tuda, Tudensis).- Vila, bispado, concello e parroquias de O Sagrario e San Martiño de Caldelas de Tui.- Provincia de PO.- 4, 6, 7, $14,15,18,19,20,21,23,28$

Turiam, tenente, 6 .

Urgillum, presbiter de, 6 .

Valadares, N. de, 29.

Valladares, N. de, 24

Veiga, N. da, 29.

Veron, hereditatem in, 3 .

Vilardeola, monte deo, 29.

Villis, N. de, 23.

Viso, N. de, 18. 


\section{BIBLIOGRAFÍA}

COMMISSION INTERNATIONALE DE DIPLOMATIQUE ET COMMISSION INTERNATIONALE DE SIGILLOGRAPHIE, Diplomatica et Sigillographica: travaux préliminaires de la Commission Internationale de Diplomatique et de la Commission Internationale de Sigillographie: pour une normalisation internationale des éditions de documents et un Vocabulaire international de la Diplomatique et de la Sigillographie, Zaragoza, Cátedra Zurita de la Institución Fernando el Católico, d.1. 1984 (Folia Caesaraugustana, 1).

FERNÁNDEZ RODRÍGUEZ, Manuel, Toronium: aproximación a la historia de una tierra medieval, Consejo Superior de Investigaciones Científicas, Instituto Padre Sarmiento de Estudios Gallegos, Santiago de Compostela, 2004.

FLORIANO CUMBREÑO, Antonio, Curso general de paleografia y diplomática españolas, Oviedo, 1946.

LOSADA MELÉNDEZ, Ma . José e SOTO LAMAS, M․ Teresa, "Oficios monásticos de Santa María de Melón", 1169-1270, Boletín de Estudios del Seminario "Fontán-Sarmiento", n 13, 1992, pp. 26-28.

LUCAS ÁLVAREZ, Manuel, "Paleografía gallega. Estado de la cuestión”, Anuario de Estudios Medievales, $\mathrm{n}^{\circ} 21,1991$, pp. 527-536.

MARÍN MARTÍNEZ, Tomás e outros, Paleografía y Diplomática, UNED, Madrid, 1978.

PÉREZ RODRÍGUEZ, Francisco Javier, Mosteiros de Galicia na Idade Media, Ourense, 2008.

ROMANÍ MARTÍNEZ, Miguel e OTERO PIÑEYRO MASEDA, Pablo Santiago, "Sobre los inicios del monasterio de Melón y sus relaciones con los monasterios de Bárcena y Canales: corpus documental", Galicia monástica. Homenaxe a María José Portela Silva, Universidade de Santiago de Compostela, 2009, pp. 23-37.

SOTO LAMAS, $\mathrm{M}^{\mathrm{a}}$. Teresa, La colección del monasterio cisterciense de Melón, Orense (Pergaminos de la Catedral de Orense). Ss. XII-XIII, Santiago de Compostela, 1992. Tesis de licenciatura inédita, Facultad de Geografía e Historia de la Universidad de Santiago de Compostela.

Nomenclátor de Galicia-Toponimia Oficial das provincias, concellos, parroquias e lugares, Xunta de Galicia, 2003. [En línea: <http://www.xunta.es/nomenclator/busca.jsp>Consulta: 29-05-2011]

Normas de transcripción y edición de textos y documentos, Madrid, Escuela de Estudios Medievales, CSIC, 1944. 